\title{
MARPs sensitization: A diversity training guide for health care providers in Nigeria
}

Enhancing Nigeria's HIV/AIDS Response (ENR) Programme

Follow this and additional works at: https://knowledgecommons.popcouncil.org/departments_sbsr-hiv

Part of the Demography, Population, and Ecology Commons, Family, Life Course, and Society Commons, Gender and Sexuality Commons, International Public Health Commons, and the Medicine and Health Commons How does access to this work benefit you? Let us know!

\section{Recommended Citation}

Enhancing Nigeria's HIV/AIDS Response (ENR) Programme. 2012. "MARPs sensitization: A diversity training guide for health care providers in Nigeria." Abuja: Enhancing Nigeria's HIV/AIDS Response (ENR) Programme. 


\section{enr}

ENHANCING NIGERIAS RESPONSE T0 HIV AND AIDS (ENR) PROGRAM

\section{MARPS Sensitization:}

\section{A Diversity Training Guide} for Health Care Providers in Nigeria

Series 1: Working with Men who have Sex with Men (MSM)

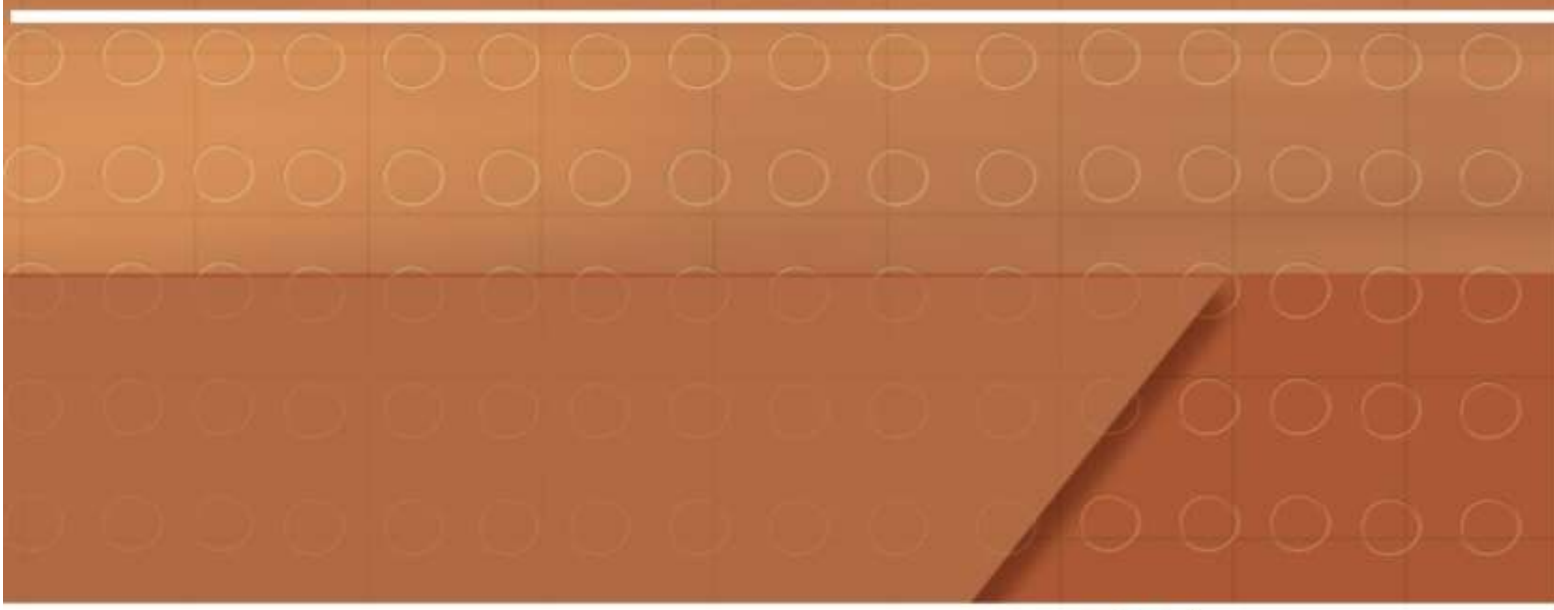

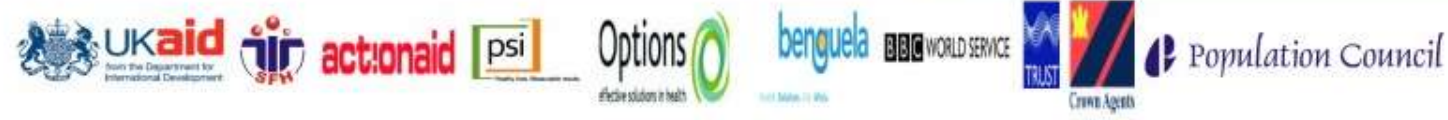


MARPS Sensitization: A Diversity Training Guide for Health Care Providers in Nigeria.

Series 1: Working with Men who have Sex with Men (MSM). 


\section{Recommended Citation:}

Enhancing Nigeria's HIV/AIDS Response (ENR) Programme. MARPS Sensitization: A Diversity Training Guide for Health Care Providers in Nigeria. Series 1: Working with Men who have Sex with Men (MSM). 2012

ISBN: 978-978-51172-2-6 


\section{ACKNOWLEDGEMENTS}

This training guide has been made possible by the combined efforts of many individuals and collaborating institutions. We gratefully acknowledge the Desmond Tutu HIV Foundation. Sections of this manual were adapted from 'Men who have sex with Men. An Introduction Guide for Health Workers in Africa' and used as a guideline for the development of this manual.

We would like to thank the United Kingdom Department for International Development (DFID) through the Enhancing Nigeria's Response to HIV and AIDS (ENR) programme, for their support in the development and printing of this manual. We thank everyone who has contributed their expertise, resources and guidance. 


\section{INTRODUCTION}

Men who have sex with men (MSM) are a diverse group presenting specific diagnostic and management challenges to counselors and healthcare providers. Anal sexual intercourse between men and their female and male partners has been shown to be an important mode of transmission of HIV within heterosexual and homosexual relationships. High prevalence of HIV infection has been reported among Men who have sex with Men (MSM) in Nigeria, this is driven partly by stigma, and discrimination, lack of specific and appropriate prevention strategies, limited research evidence, little recognition by policy makers and inadequate knowledge and skills in dealing with MSM clients. With the state of legal provisions in Nigeria, which makes homosexuality illegal, the risk embodied in same-sex activities is high and makes hiding of MSM activities almost a norm.

Currently, health care provider training materials that address MARPs specific health needs such as HIV risk infections and the acquisition of anal STIs are non-existent in Nigeria. Knowledge of these will enable counselors and healthcare providers adequately provide prevention and treatment services to men who engage in high risk sexual practices.

This training, which is part of a series of manuals for MARPs, will equip all health care providers to enable them to improve health care provision for MSM.

\section{Goal}

This training manual aims to educate and equip health care providers with the necessary skills and knowledge to provide health services that support and adequately cater for MARPs particularly MSM and their unique needs within Nigerian health care setting.

This curriculum has been adapted for use by HCP to increase their understanding of MARPs (MSM)-related health issues and expand their capacity to provide responsive care in a supportive and non-stigmatizing environment.

\section{Target audience}

This training programme is for doctors, nurses, HIV counselors, laboratory scientists and other health care providers who operate in Nigeria and have varying degrees of working experience with MARPs. It has been designed specifically for individuals who already have a basic understanding and experience in HIV prevention, treatment and care sector. 


\section{Learning outcomes}

After completing the training, participants should be able to:

- Discuss the HIV vulnerabilities of Most-at-Risk-Populations (MARPs).

- Understand the roles and responsibilities of health care providers (HCP) towards MARP communities in Nigeria.

- Describe stigma and the impact discrimination has on MSM.

- Understand sexual orientation and the differences between sexual identity, behaviour and orientation, and understand how these relate to men.

- Describe common sexual practices of MSM and understand the importance of taking a sexual history and asking clients about their sexual practices.

- Explain how HIV and STI related issues specifically impact on their sexual health.

- Discuss various ways of making risk-reduction counselling, testing and other health care services more sensitive to the needs of MSM.

\section{Curriculum Format}

The curriculum is divided into nine modules that should be completed sequentially. A pre and post-test assessment has been included to measure levels of experience, knowledge and attitudes before and after completing the course. A post-training commitment is included at the end of the programme in order to encourage participants to commit to applying the lessons learnt in the field.

\section{Module Structure}

Each module begins with a statement of learning outcomes that help identify key knowledge and important skills that the participant should have acquired and feels comfortable to apply after completing each module. A brief summary is also included that reviews basic information, important facts and skills covered in the module.

Many modules include exercises and reflection tasks in order to provide an opportunity for personal reflection and assessment of knowledge, attitudes and beliefs. Furthermore, practical case studies are presented in story format throughout the manual. The case studies are based on real life experiences and provide an opportunity for participants to practice newly learned skills and knowledge. At the end of each module, the learning objectives are revisited and important facts and lessons are reinforced. 


\section{Certification}

Successful completion of the training programme implies that counsellors are familiar with core knowledge and feel comfortable to counsel any MSM in an enlightened manner.

\section{The importance of keeping an open mind and learning attitude}

Participants taking part in this training programme may have developed certain perceptions and opinions about certain MARPs particularly MSM based on personal beliefs and ideals. Both positive and negative assumptions about these populations can impact the ability to effectively counsel any MARP client. It is pertinent that counsellors provide services to all clients in a nonjudgmental way. The interests of the client should be the priority of any counselling session. Respect should be shown to all clients and confidentiality of all sessions is of utmost importance. This training will also attempt to assist counselors and healthcare providers to overcome personal barriers that may affect their ability to address the specific needs of MARPs in Nigeria.

\section{Facilitator guidelines}

The following guidelines have been provided for use by facilitators who will use this manual to conduct group training.

\section{Introduction}

1. Briefly welcome the participants and introduce yourself.

2. Provide a concise overview of the training goals.

3. Ask participants to introduce themselves by stating the name they wish to be known by during the sessions.

4. Attend to any necessary housekeeping arrangements i.e. logistics, tea/lunch breaks, toilet location, etc.

5. Explain that the issue of working with MARP communities is potentially sensitive hence, in order to contribute to discussions people will need to feel safe enough to express their thoughts and feelings and feel secure that confidentiality will be respected.

6. Begin with a process of setting ground rules, acknowledging that the discussions of sexual behaviour can be difficult and that people are under no obligation to speak from personal experience on these issues. 


\section{Suggested ground rules}

(Ask participants to suggest ground rules, add any that are missing.)

- We will value differences of opinion and experience.

- We will keep everything shared within this workshop confidential.

- We will arrive on time to show respect to other people in the group.

- We will seek to practice active listening.

- We will put our mobile phones on silent mode and close our laptops during sessions.

- Any others...?

\section{What we will achieve in this training}

- Many people have values, religious beliefs and prejudices that hinder their capacity to provide services that are grounded in public health and human rights principles. We will explore our own attitudes and feelings about working with MSM.

- We will make our services and professional behaviour more "MARPs-friendly".

- We will increase our understanding of specific needs of MSM within the context of the HIV epidemic.

\section{Facilitation skills}

- Review what you will do before you start facilitating. This gives you confidence in what you are doing.

- Arrive at the venue earlier than everyone so you can set up the seating arrangements.

- Prepare in advance what you will need for the duration of your session (Photocopies, projector, energizers etc)

- Remember to pay attention to all participants.

- Do not interrupt while people are talking and always check group participation.

- A facilitator is not a teacher, which means that in a lot of situations there is no wrong or right answer. A facilitator 'facilitates' or helps others to discover what they know and to find their own solutions.

- Facilitators must empower the participants and give them the skills to think about their own feelings and cope with them.

- Use summary and reflection to make sure that all participants understand what is being discussed.

- Remember that it is fine to say: 'I don't know' to a question.

- Remember cooperation, patience and leadership skills while working with facilitators and the group. 


\section{Make participants feel welcome}

Greet participants when they arrive and be mindful throughout the session of using both a tone of voice and gestures that will create a safe environment.

\section{Be sensitive to people of varying levels of knowledge and backgrounds}

Participants may differ in terms of culture, religion, values, age, gender, working conditions and educational backgrounds. Encourage mutual respect among and between participants.

\section{Respect everyone's opinions}

It is important that individuals feel free to express their views and opinions in the sessions. However, be aware that some people may express opinions that are offensive to others. Encourage all participants to respect each other's views and feelings. Encourage constructive debate. If participants disagree with each other, or with you, it is important to facilitate an open discussion.

\section{Stay focused and on time}

Encourage participants to discuss and share experiences, but try to keep group discussions focused on the topics you are covering and within the time you have for each activity.

\section{Be flexible but efficient}

There is a lot of material to cover in the curriculum, so you will have to find a balance between giving space to the participants to express their feelings and views, and making sure that all the sections are addressed. Be flexible enough to adapt the content and time allowances for each section according to how participants respond in each session.

\section{Be prepared}

Plan your session carefully and know exactly what you are going to cover. To do this, you will need to read the reference materials carefully with objectivity.

\section{Allow space in the discussion for people to share their experiences}

Participants who are comfortable sharing their experiences, either in a personal or professional capacity, may be able to help others grow and enrich the group's learning. 


\section{Encourage broad and active participation}

Notice who is quiet and who responds the most frequently; try to encourage input from everyone.

\section{Build an honest relationship with participants}

Share your views and ideas. If you don't know something, say so. Ask if someone else in the room can make inputs. This will encourage participants to talk freely and express their own ideas and opinions.

\section{Always take the time to:}

- Remind the group about important points.

- Emphasize your main ideas throughout the session.

- Summarize the discussion and link relevant ideas.

\section{Talking about MSM}

It is important that you present the information contained in the session in a non-judgmental and professional way. It can however, be difficult sometimes to cope with your own experiences and beliefs about MSM, sexuality and personal choices, as well as those of others.

\section{Dealing with hostility}

Discussing about MSM and their same-sex behaviour could be quite emotional and highly sensitive. Hence, some participants may not want to talk about them, and may not like the way you present them. It is often hard for people to confront their own attitudes and behaviour. Remember that people find change difficult and it is natural for them to resist it. To deal with resistance and hostility, you will have to be open about your expectations of the training. Not everyone will change his or her mind within one session. Do not get drawn into arguments rather, encourage participants to debate the issues within a context of acceptable guidelines and respect for the facts.

A good facilitator should:

- Remain neutral and resist reacting strongly to participant's opinions.

- Be an active listener.

- Ask questions instead of making demands.

- Encourage open communication.

- Keeps the group focused on the issues being discussed. 


\section{Dealing with emotional aspects of the training}

One way of dealing with the emotional aspects of is to lay down ground rules at the beginning of the course to help shape discussion. (See ground rules section.)

The following are some useful tips to help you cope if people express negative emotions during the training:

- Remind the group that discussions about MSM and related topics can bring up strong feelings of anger, disgust and embarrassment. These are normal.

- Decide how the group can show support: allow them to share their feelings, take a break and/or give them time to talk to you or someone else privately. Make sure that you are able to refer participants for counselling if anyone feels the need to talk to someone after the training.

\section{Support for you, the facilitator}

It is not only the training participants who will be examining and re-examining personal values, beliefs and choices during this course. As a facilitator your job can be the most taxing because you are immersed in the same training content as the participants, but need to remain neutral and guide the group through the course by maintaining a learning-appropriate tone. This does not mean you are not allowed to have feelings; but you will need to deal with them outside of the classroom. Remember that if you are presented with problems that you are unable to deal with, you can refer participants to the appropriate services and people.

\section{Duration of Training Workshop}

Three days

\section{Training Methodology}

Facilitator presentations, brainstorming, role-plays, group discussions, case studies

\section{Materials needed}

Flip charts and stand, laptop, projector, markers, Post-It sticky notes, masking tape, printer, photocopies 


\section{Glossary}

\begin{tabular}{|c|c|}
\hline Alcohol & $\begin{array}{l}\text { This includes beer, wine and spirits. These substances act as a central } \\
\text { nervous system depressant. Alcohol is usually ingested orally as a drink }\end{array}$ \\
\hline Anal sex & $\begin{array}{l}\text { Sex which usually involves the insertion of the penis into the anus } \\
\text { (penile-anal penetrative sex) }\end{array}$ \\
\hline $\begin{array}{l}\text { Antiretrovirals } \\
\text { (ARVs) }\end{array}$ & Medication used in the prevention or treatment of HIV \\
\hline Anus & $\begin{array}{l}\text { The region of the bowels which opens onto the skin and through which } \\
\text { defecation occurs }\end{array}$ \\
\hline Bisexual & Having sexual partners of both the same and the opposite sex \\
\hline Bisexuality & $\begin{array}{l}\text { The sexual orientation in which an individual has romantic and/or sexual } \\
\text { feelings towards both males and females at a point in time. }\end{array}$ \\
\hline Chancroid & $\begin{array}{l}\text { STI caused by the bacterium Haemophylis ducreyi, resulting in } \\
\text { ulceration and swollen lymph nodes }\end{array}$ \\
\hline Chlamydia & $\begin{array}{l}\text { A group of sexually transmitted bacteria commonly responsible for } \\
\text { urethritis/proctitis }\end{array}$ \\
\hline $\begin{array}{l}\text { Cocaine/crack } \\
\text { cocaine }\end{array}$ & $\begin{array}{l}\text { Substances derived from the coca plant which act as a central nervous } \\
\text { system stimulant, which can be snorted, injected or smoked }\end{array}$ \\
\hline Coming out & $\begin{array}{l}\text { The process of coming to terms with one's own sexuality (sexual } \\
\text { orientation and sexual identity) }\end{array}$ \\
\hline Concurrent partners & Having more than one sexual partner at the same time \\
\hline Discharge & $\begin{array}{l}\text { Fluid oozing from an area of inflammation, which includes cells aimed } \\
\text { at fighting infection and the infectious agent. Discharge may be seen } \\
\text { coming from the penis, anus, vagina or throat as a result of selected } \\
\text { sexually transmitted infections }\end{array}$ \\
\hline Co-infection & $\begin{array}{l}\text { This is given when an individual presents with signs and symptoms for } \\
\text { two co-occurring conditions, each requiring treatment and management }\end{array}$ \\
\hline Ecstasy & $\begin{array}{l}\text { This belongs to the class of drugs known as amphetamines, which act as } \\
\text { a central nervous system stimulant. They are usually ingested orally, but } \\
\text { can also be snorted, smoked, injected or inserted anally }\end{array}$ \\
\hline $\begin{array}{l}\text { Ejaculation } \\
\text { fluid(cum) }\end{array}$ & $\begin{array}{l}\text { Fluid released from the penis during ejaculation ('cumming'). Many } \\
\text { viruses and bacteria which are responsible for sexually transmitted } \\
\text { infections can be present in this fluid }\end{array}$ \\
\hline Female condom & $\begin{array}{l}\text { Loose-fitting polyurethane sheath with an inner ring at the closed end, } \\
\text { and an outer ring at the open end, inserted inside the vagina or anus, for } \\
\text { protection against pregnancy and/or HIV and STIs }\end{array}$ \\
\hline Fingering & $\begin{array}{l}\text { Using one or more fingers to stimulate the genitals, including the } \\
\text { insertion of the fingers into the anus or vagina }\end{array}$ \\
\hline Frottage & Rubbing penises together for sexual stimulation \\
\hline Gay man & $\begin{array}{l}\text { A man who has romantic, sexual and/or intimate feelings for other men. } \\
\text { 'Gay' is generally a more commonly used term for homosexual. The } \\
\text { term men who have sex with men (MSM) should be used unless } \\
\text { individuals or groups self-identify as gay. }\end{array}$ \\
\hline
\end{tabular}




\begin{tabular}{|c|c|}
\hline $\begin{array}{l}\text { Gender/biological } \\
\text { sex }\end{array}$ & $\begin{array}{l}\text { The term biological sex refers to biologically determined differences, } \\
\text { whereas gender refers to differences in social roles and relations. } \\
\text { Gender roles are learned through socialization and vary widely within } \\
\text { and between cultures }\end{array}$ \\
\hline Gender identity & $\begin{array}{l}\text { A person's sense of self as male or female. While most people's gender } \\
\text { matches their biological sex, someone may be born biologically male, } \\
\text { yet have a female gender identity }\end{array}$ \\
\hline Genital & Relating to sexual organs \\
\hline Gonorrhea & $\begin{array}{l}\text { A sexually transmitted infection caused by the bacteria Neisseria } \\
\text { gonorrhoea, commonly affecting the penis, anus and vagina, and less } \\
\text { commonly the throat }\end{array}$ \\
\hline Group Sex & Sexual behaviour involving more than two participants \\
\hline Heroin & $\begin{array}{l}\text { This substance belongs to the class of drugs known as opiates, which act } \\
\text { as a central nervous system depressant and analgesic. It is usually taken } \\
\text { intravenously (injected) }\end{array}$ \\
\hline Hepatitis & $\begin{array}{l}\text { Inflammation of the liver, which may be caused by a virus, drugs or, } \\
\text { rarely, diseases of the immune system }\end{array}$ \\
\hline Herpes & $\begin{array}{l}\text { A group of viruses which are spread through direct contact. Herpes } \\
\text { simplex type } 1 \text { is responsible for 'cold sores' - superficial ulcers around the } \\
\text { mouth and nose. Herpes simplex type } 2 \text { causes most cases of painful sores } \\
\text { found around the penis, anus or vagina (genital herpes) }\end{array}$ \\
\hline Heterosexuality & $\begin{array}{l}\text { The sexual orientation in which an individual has romantic or sexual } \\
\text { feelings towards members of the opposite sex }\end{array}$ \\
\hline Homophobia & $\begin{array}{l}\text { Discrimination, stigma, fear or hatred based on homosexuality, directed } \\
\text { at gays, lesbians, bisexuals and transgender people }\end{array}$ \\
\hline Homosexuality & $\begin{array}{l}\text { The sexual orientation in which an individual has romantic or sexual } \\
\text { feelings towards members of the same sex }\end{array}$ \\
\hline $\begin{array}{l}\text { Human papilloma } \\
\text { virus (HPV) }\end{array}$ & $\begin{array}{l}\text { The virus responsible for genital warts. Different subtypes exist, some of } \\
\text { which are associated with the development of anal, penile and cervical } \\
\text { cancer }\end{array}$ \\
\hline IDU & Injecting Drug Users \\
\hline Incidence & $\begin{array}{l}\text { The number of new people who develop a condition during a particular } \\
\text { period of time. }\end{array}$ \\
\hline $\begin{array}{l}\text { Insertive } \\
\text { partner('top') }\end{array}$ & $\begin{array}{l}\text { In anal sex, the partner who is inserting his penis into the other partner's } \\
\text { anus }\end{array}$ \\
\hline Intersexed people & $\begin{array}{l}\text { Previously referred to as 'hermaphrodites', this refers to individuals who } \\
\text { are born with a combination of both male and female reproductive } \\
\text { organs, chromosomes, and/or hormones that are either fully or partially } \\
\text { developed }\end{array}$ \\
\hline Lesbian & $\begin{array}{l}\text { A woman who has romantic, sexual and/or intimate feelings for other } \\
\text { women. The term women who have sex with women (WSW) should be } \\
\text { used unless individuals or groups self-identify as lesbians }\end{array}$ \\
\hline LGBTI & Abbreviation for 'lesbian, gay, bisexual, transgender, intersex' \\
\hline Lubricant & $\begin{array}{l}\text { Substance, which reduces friction during sexual intercourse. Lubricants } \\
\text { can be water based (e.g. K-Y Jelly®) or oil-based (e.g. Vaseline®, body } \\
\text { cream, cooking oil). Latex male condoms should only be used with }\end{array}$ \\
\hline
\end{tabular}




\begin{tabular}{|c|c|}
\hline & water-based lubricants, as oil-based ones weaken latex. \\
\hline Lymph nodes & $\begin{array}{l}\text { Glands that form part of the immune system and are involved in fighting } \\
\text { infection. Major groups of glands exist in the inner thigh, in the armpits } \\
\text { and in the neck. }\end{array}$ \\
\hline Male condom & $\begin{array}{l}\text { A rubber sheath made of latex, polyurethane or Nitrile placed over the } \\
\text { erect penis before sexual intercourse which prevents pregnancy and } \\
\text { HIV/STIs by blocking the exchange of sexual fluids. }\end{array}$ \\
\hline Marijuana (Weed) & $\begin{array}{l}\text { This substance acts as a central nervous system depressant and } \\
\text { hallucinogen and is usually inhaled by smoking it, but can also be } \\
\text { ingested orally. }\end{array}$ \\
\hline Methamphetamine & $\begin{array}{l}\text { This includes speed, crystal meth, which act as a central nervous system } \\
\text { stimulant and can be snorted, ingested orally, injected or smoked. }\end{array}$ \\
\hline MSM & $\begin{array}{l}\text { Men who have sex with men. This term includes not only men who self- } \\
\text { identify as gay or homosexual and have sex only with other men but } \\
\text { also bisexual men as well as men who self-identify as heterosexual but } \\
\text { have sex with other men. }\end{array}$ \\
\hline Multiple stigma & $\begin{array}{l}\text { Stigmatizing because of two or more perceived differences, e.g. sexual } \\
\text { orientation, HIV-positive status and race. }\end{array}$ \\
\hline Oral sex & $\begin{array}{l}\text { Contact between the mouth and tongue and genitals (penis, testicles, anus, } \\
\text { vagina), which includes licking, sucking, kissing. }\end{array}$ \\
\hline Oro-anal sex & $\begin{array}{l}\text { Contact between mouth, tongue and anus, including licking (rimming) and } \\
\text { kissing the area around the anus and rectum. }\end{array}$ \\
\hline $\begin{array}{l}\text { Penetrative penile- } \\
\text { anal sex }\end{array}$ & $\begin{array}{l}\text { Sex act describing the positioning or role of the 'active' partner or 'top' } \\
\text { whose penis is being inserted into the anus of his sexual partner. }\end{array}$ \\
\hline Phobia & Excessive anxiety or fear about a specific object or situation \\
\hline Prevalence & $\begin{array}{l}\text { The number of people who currently have a particular condition within a } \\
\text { particular period of time. }\end{array}$ \\
\hline Prostate & $\begin{array}{l}\text { A large internal gland which surrounds the urethra at the base of the } \\
\text { bladder which produces some of the liquid and substances found in } \\
\text { ejaculation fluid }\end{array}$ \\
\hline Proctitis & $\begin{array}{l}\text { Inflammation of the rectum, commonly due to a sexually transmitted } \\
\text { infection in the rectum }\end{array}$ \\
\hline Prostatitis & Inflammation of the prostate commonly due to an infection. \\
\hline Receptive anal sex & $\begin{array}{l}\text { Sex act describing the positioning or role of the 'passive', 'receptive', } \\
\text { 'bottom' whose anus is being entered }\end{array}$ \\
\hline $\begin{array}{l}\text { Receptive partner } \\
\text { ('bottom') }\end{array}$ & $\begin{array}{l}\text { In anal sex, refers to the partner whose anus is being penetrated by the } \\
\text { other partner's penis }\end{array}$ \\
\hline Rectum & $\begin{array}{l}\text { The lower region of the bowels linking the descending colon to the anus } \\
\text { - also referred to as the rectal passage }\end{array}$ \\
\hline Rimming & Licking/kissing the anus with the tongue/mouth (see oro-anal sex) \\
\hline $\begin{array}{l}\text { Sero-discordant } \\
\text { relationship }\end{array}$ & $\begin{array}{l}\text { A romantic or sexual relationship between two people with different } \\
\text { HIV status }\end{array}$ \\
\hline Sexual behaviour & $\begin{array}{l}\text { The manner in which people express their sexuality, examples of this } \\
\text { behaviour can include physical or emotional intimacy and sexual contact }\end{array}$ \\
\hline Sexual orientation & $\begin{array}{l}\text { The term used to describe the set of emotional, physical and romantic } \\
\text { feelings an individual has towards others. These feelings and behaviours }\end{array}$ \\
\hline
\end{tabular}




\begin{tabular}{|c|c|}
\hline & are usually directed towards men or women, or both men and women. \\
\hline $\begin{array}{l}\text { Sexually transmitted } \\
\text { infection (STI) }\end{array}$ & Infection transmitted and acquired through unprotected sexual contact. \\
\hline Stereotype & $\begin{array}{l}\text { To perceive all members of some group as if they all were all identical, } \\
\text { e.g. to see all MSM as being effeminate. }\end{array}$ \\
\hline Stigma & $\begin{array}{l}\text { Shame or disgrace attached to something regarded as socially } \\
\text { unacceptable. }\end{array}$ \\
\hline Stigmatize & $\begin{array}{l}\text { The action of treating someone differently or unfairly because of some } \\
\text { perceived difference (e.g. sexual behaviour, gender). }\end{array}$ \\
\hline Substance abuse & A pattern of repeated substance use despite the negative consequences. \\
\hline Symptom & Feeling or problem as experienced by a client, participant or individual. \\
\hline Syphilis & $\begin{array}{l}\text { A sexually transmitted infection caused by Treponema pallidum, one of the } \\
\text { 'genital ulcer diseases'. }\end{array}$ \\
\hline Thigh sex & The act of rubbing the penis between the partner's thighs \\
\hline Transactional sex & $\begin{array}{l}\text { The process of exchanging sex for goods, money shelter, food or other } \\
\text { items or services. }\end{array}$ \\
\hline Transgender & $\begin{array}{l}\text { A person who has a gender identity that is different from his or her sex at } \\
\text { birth. Transgender people may be male to female (female appearance) or } \\
\text { female to male (male appearance). It is preferable to describe them as 'he' } \\
\text { or 'she' according to their gender identity, i.e. the gender that they are } \\
\text { presenting, not their sex at birth. }\end{array}$ \\
\hline Transphobia & $\begin{array}{l}\text { The fear, rejection or aversion, often in the form of stigmatizing } \\
\text { attitudes or discriminatory behaviour, towards transsexuals, transgender } \\
\text { people and transvestites. }\end{array}$ \\
\hline Transvestite & $\begin{array}{l}\text { A person who wears clothes associated with the opposite gender in order } \\
\text { to enjoy the temporary experience of membership of the opposite gender. } \\
\text { A transvestite does not necessarily desire a permanent sex change or other } \\
\text { surgical reassignment. }\end{array}$ \\
\hline Transsexual & $\begin{array}{l}\text { A person is in the process of or has undertaken surgery and/or hormonal } \\
\text { treatment in order to make his or her body more congruent with his or her } \\
\text { preferred gender. }\end{array}$ \\
\hline Ulcer & $\begin{array}{l}\text { A sore which involves a break in the protective covering provided by } \\
\text { skin. }\end{array}$ \\
\hline $\begin{array}{l}\text { Unprotected anal } \\
\text { intercourse }\end{array}$ & $\begin{array}{l}\text { Anal sex, penis in anus, which occurs without the protection provided } \\
\text { by a condom. }\end{array}$ \\
\hline Vaginal sex & $\begin{array}{l}\text { Sex which usually involves the insertion of the penis into the vagina } \\
\text { (penile-vaginal penetrative sex). }\end{array}$ \\
\hline Warts & $\begin{array}{l}\text { Growths on the skin, caused by the human papilloma virus which is } \\
\text { responsible for warts in the genital area. }\end{array}$ \\
\hline
\end{tabular}




\section{Module 1: Most at Risk Populations (MARPs) and HIV/AIDS in Nigeria}

\section{Learning outcomes}

By the end of this module, you should be able to:

- Define MARPs.

- Summarize what is known about HIV risks among MARPs in Nigeria.

- Explain why MARPs in Nigeria are more vulnerable to HIV infection.

- Understand how MARPs contribute to HIV infection among the general population.

- Understand barriers that MARPs may encounter in seeking HIV services.

\section{Introduction}

In this module, you will be provided with an overview of MARP groups in Nigeria. Specifically, in a health related context, we will be reviewing their HIV risks, vulnerabilities, and possible ways to address their health needs.

\section{Knowledge Section}

\section{Who are Most-at-Risk Populations (MARPs) in Nigeria?}

Most-at-risk populations for HIV/AIDS (MARPs) are those sub-groups that carry a higher chance of contracting or transmitting the AIDS virus because of the high risk behaviours they often engage in such as high rates of unprotected sexual practices often with multiple sex partners, alcohol and substance abuse often with shared equipment and drug preparations. These population groups include female sex workers (FSWs) and their clients; injecting drug users (IDUs); and men who have sex with men (MSM). In its recent report on the global AIDS epidemics, UNAIDS highlighted four key populations that tend to have a higher HIV prevalence compared with the general population which deserves increased attention. These are sex workers, MSM, IDUs and prisoners.

\section{MARPs and HIV in Nigeria}

\section{Sex Workers (Females and Males) and their Partners}

The UNAIDS define sex workers as "female, male and transgender adults and young people who receive money or goods in exchange for sexual services, either regularly or occasionally, and who may or may not consciously define those activities as income-generating". The term sex worker has gained popularity over prostitute because those involved feel that it is less stigmatizing and say that the reference to work better describes their experience. 
Sex work is a highly stigmatized and criminalized practice in Nigeria. As a result, many sex workers operate clandestinely, although an increased presence of young men and women who engage in sex work are noticeable in designated spots in many Nigerian cities such as Abuja, Lagos and Port Harcourt. Male sex workers (MSW) may identify themselves as homosexual, heterosexual or transsexual, regardless of their personal sexual identity, they frequently engage in various sexual acts depending on their clients. In many African countries, there is often a profound denial by government officials and society at large that women would consider paying a man for sexual services or that a man would have intercourse with another man. Little is known about the locations and size of this population. A research study by Population Council on Male sex workers (MSWs) in Nigeria shows that on any given Friday night in Lagos, an estimated 865 men are willing to engage in sex for money or goods with other men. In Kano on any given Saturday night, 641 men are willing to engage in sex for money or goods with other men, In Port Harcourt on typical Friday night, 358 men are willing to engage in sex for money or goods with other men. Female sex workers (FSWs) in Nigeria broadly consist of two groups - brothel-based and non-brothel based. The brothels for sex work activities are usually located in low rated "hotels' with bars where women rent rooms. In some of the cases, the "hotels" are conveniently located where clients can be easily recruited such as major markets and motor parks. Sex work could be of direct type (where sex work is the primary economic activity) or indirect sex work (where sex work is a supplementary economic activity with the sex worker primarily engaged in occupation). The number of males and females engaged in sex work in the country is not know, No register is known to be maintained even for brothel-based sex workers. The increasing economic difficulty in the country, rising unemployment, and the high cost of living in major cities like Abuja, Lagos and Port Harcourt may also be a strong driver for the sex industry. MSW and FSWs are usually between late teenage years and forty in age.

Clients of MSW and FSW vary in nature and background considerably, depending on the geographic location, age, and other characteristics of the sex worker (e.g. if s/he is involved in direct or indirect sex work). For the brothel-based FSW, transport workers (including drivers, motor park touts, small business owners and commercial motor cycle riders) are ranked among the most common customers. While brothel-based FSW's clients go to meet them at their locations, non-brothel-based FSW and MSW meet their clients in the streets particularly around popular junctions, hot spots, bars, entertainment centres and also use social media and mobile phones to set up.

\section{HIV Prevalence, Knowledge and Risks}

Male Sex Workers are a highly marginalized population in Nigeria. Stigma, secrecy, and HIV risk are highly associated with this lifestyle; there is also low condom use among MSW, which is particularly worrisome because of the increased risk of HIV transmission associated with anal sex. Male sex workers are also found to have low condom use rates with their female clients. Studies show HIV prevalence for MSM at $13.5 \%$, and over 30\% among the subset of MSWs (IBBSS 2007). With over $25 \%$ of all FSW infected with HIV, they have been identified as the sub-population most infected with HIV and AIDs in Nigeria. Although condom use in commercial sex is reported to be high (IBBSS 2010), condom use with boyfriends and casual partners is considerably lower. Given that FSWs engaging in multiple partnerships, they are identified as a significant bridge for HIV transmission to the general population. Most MSW and FSWs do not perceive themselves as being at risk of $\mathrm{HIV}$ and alcohol and drug use is also rife within the sex worker communities. 


\section{Men who have sex with Men (MSM)}

MSM is an inclusive public health term used to define sexual behaviour of men having sex with other men. It is the preferred term in the context of HIV because the important issue is risk behaviour rather than sexual identity. It does not refer to an identifiable community or gender identification. Men who have sex with men (MSM) includes not only self-identified gay/homosexual and bisexual men, but also men who engage in anal sex with other men and self-identify as heterosexual and also with women. For example, in certain situations, such as in prisons or military service may also encourage result in engage in anal sexual intercourse among men who would not do so in other contexts.

According to UNAIDS, since many men who have sex with men engage in anal sex and often have multiple sexual partners, male-to-male transmission is an issue of great importance in HIV prevention. In Nigeria, MSM activities are often carried out in clandestine manner and many MSM do not disclose their sexual identity. As a result, many MSM in Nigeria are bisexual which increases their risk of transmitting HIV to their spouses or other female sex partners. With the state of legal provisions in Nigeria, which makes homosexuality illegal, the risk embodied in same-sex activities is high and makes hiding of MSM activities almost a norm. MSM face a lot of discrimination in Nigeria. Even health workers attitude to an infected person is likely to be more negative if the individual was found to have been infected with HIV or other STIs through anal sex. There are, however, some visible MSM in the country. The number of MSM in the country is currently unknown. Settings where MSM activities are common include the male-only schools and camps, armed forces and the prisons. Experiences of MSM have been found to be diverse, with ethnic, religious and class distinctions strongly structuring sexual expression.

\section{HIV Prevalence, Knowledge and Risk}

Next to FSW, MSM have the highest HIV prevalence within Nigeria of 17.2\%. According to the 2010 IBBSS, MSM represent a diverse group of people who engage in sex for different reasons, sexual preference, economic benefit, situational and sexual assault. Because of sexual cultural taboos and lack of legal protection, they are also a highly stigmatized population with limited access to relevant information and services appropriate to their needs. Exposure to interventions among MSM is reported to be very low, with very few receiving safe sex education from peer or outreach workers and accessing HIV counselling and testing. Due to stigma, they are likely to be difficult to reach, and often may be married to women, with children thus, increasing the risk of HIV spreading into the general population.

\section{Injecting Drug Users (IDUs)}

HIV transmission through injecting drug use is an increasingly serious public health problem in many countries and regions. Up to $10 \%$ of all HIV infections worldwide are contracted from contaminated needles or other injecting equipment and globally, 22\% of the world's HIV/AIDS population inject drugs. The great majority of such infections are associated with intravenous, and generally illegal, drug use. Drugs used by IDUs are of a wide variety including cocaine, amphetamines, tranquillizers, barbiturates as well as other pharmaceutically produced opiates of which heroin is the most common and well known. The use of contaminated equipment for 
intravenous drug administration is a more efficient way of contracting HIV than almost any other. In addition, IDUs also contribute to HIV transmission to the general population through sexual relationship with male and female partners, and may even transmit the infection to newborn children through mother-to-child route. There is a strong linkage between sex work and drug use as IDUs can exchange sex for drugs or engage in sex work to support their drug use habit. The number of IDUs in Nigeria is not known. A joint study between the World Health Organization (WHO), the Ministry of Health and the University of Ilorin on drug abuse concluded that injecting drug use with associated health consequences was an emerging problem in Lagos, Nigeria. There are indications that heroin and cocaine use has increased in Lagos and other big cities in Nigeria in the past 5-10 years. Informal reports suggest that the city of Lagos has some 50-100,000 injecting drug users. With the fact that a major route between Asia, Europe and North America runs through Nigeria, there is the potential that the IDUs population may grow with time.

\section{HIV Prevalence, Knowledge and Risk}

IDUs have the third highest prevalence after FSW and MSM in Nigeria. IDUs are considered at higher risk of contracting and spreading HIV primarily through the sharing of needles and syringes, as well as practicing unsafe sex. IDUs are also known to be sexually active with both girlfriends and with FSWs. Many female IDUs also sell sex, increasing the risk of HIV spreading into the general population through their clients. Because their behavior is illegal, it is difficult to reach IDUs with appropriate information, condoms, services, and harm reduction measures including access to safe needles and rehabilitation services.

Figure 1 showing HIV prevalence among MARPs in Nigeria: (IBBSS 2007/10)

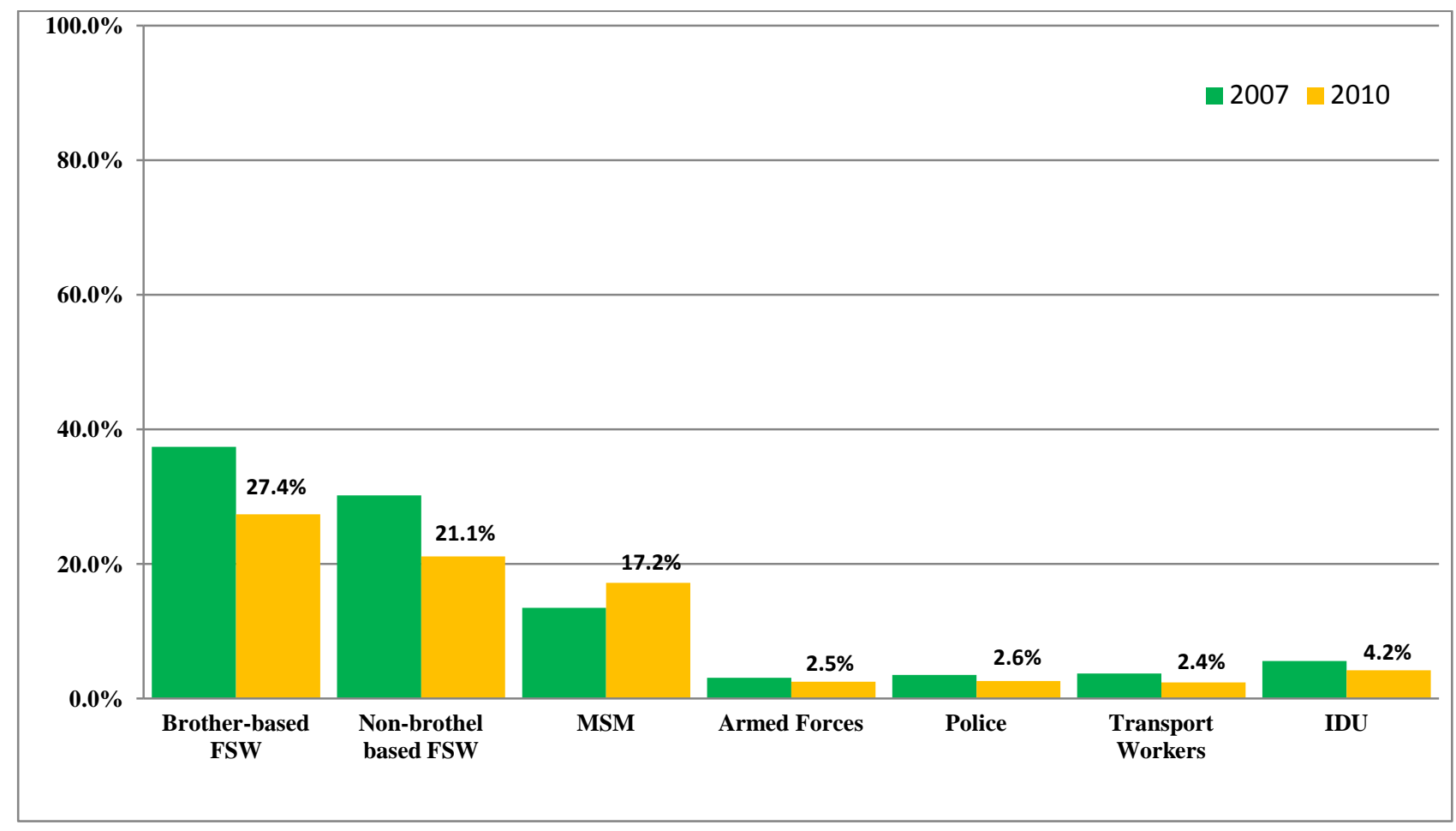


Exercise 1: In small groups, describe the HIV risks of each MARP group and societal factors that may increase their HIV vulnerability.

Exercise 2: Role Play: Discussing MSM behavior

Scenario:

Counsellor/health care provider: A man has come to you to request an HIV test, for which you are providing pre-test counselling.

Man: You are a 30-year old married man with two children, and you are now trying for a third baby. You and your wife tested negative during her last pregnancy. In the last year, you have also started a sexual relationship with a man. You have kept this relationship hidden as it is frowned upon in your community.

In groups, discuss the following.

- How did you come to discuss the relationship with another man? Was this information volunteered by the man or prompted by questions from the counselor?

- From the man's perspective, what did the counselor do or say that made you feel comfortable to discuss this relationship?

- From the counselors perspective, what aspects (if any) of this discussion did you find difficult and why? What would have made this easier? Did you find out what you needed to know to offer the right professional advice to this man? 
Module 2: Role and Responsibilities of Health Care Providers

\section{Learning Outcomes}

At the end of this module, participants should be able to:

- Understand their roles in addressing HIV prevention and other health issues among MSM.

- Understand how their attitudes affect MSM health seeking behavior.

- Understand the reasons for their behavior.

- Understand what needs to be done to improve their behavior towards MSM.

\section{Introduction}

In this module, you will learn about how HCPs attitudes influence effective HIV prevention, treatment, care and support for MSM in Nigeria

\section{Knowledge section}

Healthcare providers have an important role to play in addressing HIV and other health issues among MSM communities in Nigeria because of their critical roles as entry points to necessary health services and influencers for effective HIV prevention, treatment, care and support. 


\section{Case Study}

Ojo started to get painful sores around his anus and went to a clinic to get tested and possible treatment, but he was worried about how he would be treated by the clinic staff. So he told the nurse that he was constipated, and that it was very painful. The nurse didn't say anything, but she left the room and a few minutes later returned with two other nurses. The nurses looked at him, whispered to each other, and then left.

When the first nurse returned, he challenged her and said, he has been waiting a long time. Could she attend to him?." She laughed and said, "Who is he to tell her what she should do? That he will just have to wait. She said this in the presence of the other patients and then left. He was later told that she and the other nurses had gone off for break. He could imagine them gossiping about him over their break and he wondered who else they would tell about him.

After a long break, he got to meet with the doctor. He explained that he had sores in his anus. Without even examining him, the doctor asked, "what have you been doing? How did you get this STI?" he also said, "what do you expect to get from this unusual sexual behaviour. I am used to treating STIs in the front, not the back. Why are you making my life difficult?" Then he told Ojo to take off his pants and he looked at his bum from a long distance away, and said, "Why do you have an STI in your anus? What have you been doing?"

He then began to ask Ojo a lot of questions about his sex life - "When was the last time you had sex? Who did you have it with? What kind of sex have you been having? When was the last time you had sex with a woman? Do you have a girlfriend? How do you have sex with a man?" Ojo told him that "I just wanted to be tested and treated, not asked about my sex life. The doctor responded that the clinic only did testing for real men, not homosexuals.

As soon as the doctor went to the next room, Ojo put his pants on and left the clinic. It was humiliating! "I will never go back to that clinic again!" Ojo went to the clinic with a medical problem to get help from the doctor, but he did not receive any treatment - all he got were insults and blame!

This exercise looks at the experience of MSM in accessing services from health facilities, and counselling services; how they are treated, the specific forms of stigma and discrimination they face, how it makes them feel, and the effect of stigma and discrimination on their health seeking behaviour.

The aim of this exercise is also to help healthcare service providers make a frank and open assessment about stigma in their own workplaces.

\section{Key issues relating to HCP attitudes towards MSM clients}

- HCPs are seen as unfriendly and judgmental towards key vulnerable populations such as young people, PLWH, FSW, MSM, IDUs, clients with STI infections andpoor people.

- HCPs do not provide accurate information and basic counselling for HIV prevention, treatment and drug adherence or refer clients to needed services.

- HCPs do not provide condoms and family planning methods when requested. 
- HCPs do not respect clients' confidentiality.

\section{Some reasons for HCPs behavior towards MSM clients}

- Religious beliefs

- Personal principles, moral judgment

- Societal norms and values

- Fear

- Poor understanding and poor knowledge

- Inadequate skills to work with MSM

\section{Some ways to improve HCPs attitude and behavior}

- Educate service providers on MARP related issues and how to deal with MSM clients.

- Changing the attitudes of service providers - to be more caring and less judgmental/stigmatizing.

- Re-affirm the code of practice i.e. treating all patients/clients equally.

- Train HCPs on basic skills in the management of STIs in MSM clients.

- Train HCPs on how to counsel patients who are sexual minorities' i.e. non-judgmental, neutral /supportive language and appropriate body language.

\section{Responsibilities of HCPs}

- HCPs need to provide friendly, non-judgmental and confidential services to all members of the society regardless of age, occupation, disability, sexual orientation, or HIV status.

- HCPs need to strengthen positive provider-client interaction, and improve service delivery in facilities and within their communities.

- Support clients access to sexual and reproductive health (SRH) products such as condoms, lubricants and other family planning methods.

- Support clients adherence to STIs and HIV related treatment.

- Support clients' access to needed care and support services through referrals.

- HCPs need to improve their role as models to reduce stigma and discrimination in the healthcare settings.

\section{HCP code of conduct}

Every individual has the need and desire for proper medical care for a variety of reasons throughout their lives and MARPs are no different and deserve the same health care as anyone else.

Under the current code of conduct for health providers in Nigeria, every patient has the right to "confidentiality" about their medical issues and anything they share with a medical practitioner unless they are causing harm to another human being or someone is causing harm to them, "privacy," during any medical exams or tests and "equal treatment" without judgment for their behavior or identity. 
Too often, MSM clients are judged, harassed, or in extreme cases denied access to basic medical care. We encourage the use of the following affirmations in your health practice, clinic or hospital to ensure equal treatment of all patients and clients

- I/we will give everyone the same type of medical care, to the highest quality possible at our facility, regardless of their gender, age, sex, socioeconomic status, sexual orientation or behaviour.

- I/we welcome everyone including sexual minorities and their families into my/our practice and offer all health services to patients on an equal basis, regardless of sexual orientation, gender identity, sexual behavior, marital status, and other non-medically relevant factors.

- I/we respect the visitation and healthcare decision-making rights of MSM patients/clients, their unmarried partners, their non-biological children, and any others they may define as family for the purposes of visitation and healthcare decision-making.

- I/we commit to taking steps to make my practice fully inclusive to MSM clients as reflected in written forms, policies and procedures, appropriate training for all clinical and administrative staff, and standardized assessments.

- I/we commit to taking steps to learn about the unique health concerns of MSM clients and families so that I/we can provide the highest quality care to all people.

- I/we will maintain confidentiality about an individual's orientation and/or behavior just as we would keep medical records of any client completely confidential

\section{Summary}

- Religious beliefs, personal values, societal norms and poor knowledge and skills influence HCPs behaviour towards MSM.

- Stigmatizing MSM communities fuels the HIV epidemic, it makes themhide their sexuality and take less care of their sexual health, increasing their risk of HIV infection, which may also bridge into the general population.

- Health providers' code of conduct requires them to treat all patients without exception. The code of conduct does not allow HCPs to refuse to treat MSM clients.

- Showing care and compassion to MSM clients can lead to them adopting a healthy and positive life and acting in their own and other people's interest.

\section{Energizer}

Stigma Bingo Game 
Module 3: Stigma and its effects.

\section{Learning outcomes}

At the end of this module, participants should be able to:

- Define stigma.

- Understand the differences between external and internal stigma.

- Relate stigma to their experience of being treated differently.

- List ways in which a person can be stigmatized for being identified as a MSM.

- $\quad$ List the effects of stigma on MSM.

- Describe homophobia.

\section{Introduction}

In this module you will learn about stigma and what it means. (You may already have heard about the stigma that is attached to people living with HIV). You will explore its multiple impacts on the different MARP groups. We will discuss homophobia, a form of prejudice directed specifically at men suspected of being MSM, especially towards those who appear to be more effeminate. Stigma may cause many forms of reaction, including violence. MSM who are HIV positive may experience the burden of double stigma, firstly because of their sexual behaviour and secondly because of their HIV status. You will find out how stigma affectsMSM in a variety of ways, from how they feel about themselves to how they live their lives, and whether or not they access health care services or HIV counselling and testing. Finally you will learn how to support a client who experiences stigmatization.

\section{$\underline{\text { Knowledge section }}$}

\section{What is Stigma?}

Stigma can be defined as, an attribute or quality that shames an individual or group of people in the eyes of another individual or group. This means that people may look at an individual and have a negative attitude towards that person because of a certain characteristic or quality, e.g. if the person is HIV positive or even just suspected of being positive, or if they are MSM or a foreigner (Engender Health, 2004).

Stigma causes certain people to be treated differently from others and this is what we mean by discrimination. Discrimination is a form of behaviour which results in unequal or unfair treatment. Stigmatizing attitudes do not always end up in discrimination, but the effect of a negative attitude is still hurtful for most at risk populations.

There are two main types of stigma - external and internal:

External stigma: causes certain people to be treated unfairly and differently than everyone else, e.g. a person who is an MSM may be refused treatment by health care providers, or be made to sit in a separate waiting area from other patients. 
Internal stigma: causes a stigmatized person to feel a certain way about him or herself as a result of experiencing external stigma. For example, a MSM may suffer low self-esteem and depression

\section{Exercise}

Think back to a time in the past when you were in any way treated differently by other people. For example, it may have been a time when you moved into a new area and attended a new school, and the students teased you for being new to the school. It may have been when you lived in an area where you were from a different group than other people around you. It could have been when you were taken care of by a distant family relative who was not your mother or father, and who treated you with less love and affection than they did their own children.

Try to remember such an experience and remember what happened. How were you treated differently? Then answer the following questions:

1. In what way were you treated differently by others around you?

2. How did this make you feel?

3. How do you think this experience affected you in the long term?

4. What did you learn from this experience?

\section{Homophobia}

Homophobia is the fear or hatred of MSM, and of lesbians, gay men and bisexuals. Homophobia often arises from prejudice and misunderstanding, and can be expressed in many forms, including contempt, discrimination and even violence. In the case of transgender people this is known as "transphobia", although transgender people may also experience homophobia.

MSM who appear to be more feminine, who cross-dress, or do not follow expected gender norms are more likely to experience homophobia, because they violate traditional expectations about what it is like to be a man. In contrast, MSM who appear to be more masculine can often 'pass' for heterosexual (i.e. be seen by others as heterosexual) and so may experience less victimization

\section{Exercise}

Draw an empty table on a piece of paper with the headings 'Causes', 'Effects' and 'Examples'. Think of the causes, effects and examples of stigma that MSM may face, then look at the table below and see if you have missed out any important ones. 
Table showing causes, effects and examples of stigma

\begin{tabular}{|c|c|c|}
\hline Causes & Effects & Examples \\
\hline $\begin{array}{ll}\text { - } & \text { Religious beliefs } \\
\text { - } & \text { Cultural beliefs } \\
\text { - } & \text { Societal norms and } \\
\text { expectations } \\
\text { - } \\
\text { - } \text { Perceived difference } \\
\text { - } \\
\text { Competition over } \\
\text { resources (e.g. jobs, } \\
\text { healthcare) }\end{array}$ & $\begin{array}{ll}- & \text { Feelings of hopelessness } \\
\text { - } & \text { Low self-worth } \\
\text { - } & \text { Substance abuse } \\
\text { - } & \text { Self-destructive behavior (e.g. not } \\
& \text { looking after health) } \\
\text { - } & \text { Lack of access to services such as } \\
& \text { healthcare }\end{array}$ & $\begin{array}{ll}\text { - } & \text { Rejection } \\
\text { - } & \text { Exclusion } \\
\text { - } & \text { Denial of services to individual MARP } \\
\text { - } & \text { Criminalization } \\
\text { - } & \text { Discrimination } \\
\text { - } & \text { Prejudice } \\
\text { - } & \text { Physical assault } \\
& \\
\text { - } & \text { Murder }\end{array}$ \\
\hline
\end{tabular}

\section{External and internal stigma}

Signs of external stigma are,

- Avoidance: people avoiding MSM or not wanting to sit near them.

- Rejection: this could be family members or friends no longer being willing to associate with the person or it could be that a society or a group of people do not welcome MSM.

- Moral judgment: people blaming MSM for their behavior and seeing them as immoral.

- Stigma by association: people who associate with MSM are also stigmatized because of their association.

- Gossip: talking about MSM in a negative way to other people.

- Discrimination: opportunities are denied to MSM such as restricting access to proper medical care, schemes and other services.

- Abuse: physically or verbally (being shouted at, called names or beaten, stoned).

- Victimization: being blamed, for example by politicians and other groups for the problems in the country.

- Disrespect for human rights: denying MSM their basic human rights such as breach of confidentiality in HIV testing, sexual history taking, refusal of service due to sexual orientation and practice.

- Violence: physical attacks which sometimes results in murder of MSM due to their sexual orientation.

Internal stigma (felt or imagined stigma) is how a person feels about themselves, e.g. shame, fear of rejection and discrimination, and depression, due to experiencing external stigma, and how they respond to these feelings.

Signs of internal stigma are:

- Self-exclusion from services or opportunities: fear of exposure as MSM, can lead to a person not wanting to access services or take up opportunities for example avoiding public healthcare facilities for fear of being treated badly due to their sexual 
orientation and practice or not running for or holding public office.

- Perceptions of self: have low self-esteem.

- Social withdrawal: withdrawal from social contacts of friends, family and colleagues.

- Overcompensation: believing that they have to contribute more than other people, or feel indebted if people are kind to them.

- Avoiding being open about their sexual orientation: fear of 'coming out' i.e. disclosure of their sexual orientation because they are afraid of the consequences.

- Mental health issues: becoming depressed or developing other mental health challenges.

- Substance abuse: excessive alcohol consumption and use of hard drugs to cope with stigma.

- Suicide: Some MSM clients, especially those who are HIV positive, may resort to killing themselves to escape the pain of stigma.

\section{Exercise}

Draw two columns on a piece of paper, labelled 'Stigma experienced by MSM' and 'Stigma experienced by people living with HIV'. Try to list as many forms of stigma under each column as possible.

Then compare the two columns. You will probably find that the kinds of stigma suffered by the two groups are very similar.

In fact, MARPs such as MSM who are also HIV positive may experience double stigma from others. They are stigmatized for being MSM and also stigmatized for being HIV positive. Without support, this may result in isolation, severe depression and even suicide.

\section{Stereotyping and making assumptions}

What is stereotyping?

Stereotyping means to perceive all members of some group as if they are all identical, e.g. to see all MSM as being effeminate, FSW as all having HIV, IDUs as all being violent. This may lead to stigmatizing behaviour. 


\section{Exercise}

1. Imagine a stereotypical soccer/football supporter. Describe what he looks like and how he might behave.

2. Do all soccer supporters look and behave like this?

No, probably not. The assumptions we make about people are often wrong. We may judge a group of people on the basis of what society tells us to believe, or based only on limited exposure to the group.

3. Now imagine a stereotypical MSM. Describe what he looks like and how he might behave.

4. Do all MSM look and behave like this? No, you can probably find evidence for many different kinds of MSM (e.g. some are effeminate, and some can 'pass' for heterosexual; some have anal sex, others do not; some are young, others are old.)

5. We can conclude that the assumptions we make about people like MSM are often wrong, and we need to be careful not to stereotype them.

\section{Addressing stigma}

How can we tackle stigma directed at MSM?

\section{Exercise}

Brainstorm a list of options, and then look at the list below.

\section{How to deal with stigma directed at MSM}

1. Treat everyone with complete respect irrespective of sexual orientation and practice. 'Treat others as you would like to be treated.'

2. Be careful to avoid using stigmatizing language towards MSM groups, both in their presence and with other community members. Words like 'homo', are usually stigmatizing.

3. Challenge other counsellors or health care providers who show stigmatizing attitudes to MSM clients by providing correct information.

4. Challenge stigmatizing attitudes towards MSM among your family and friends.

5. Become more knowledgeable about MSM communities. Knowledge reduces ignorance, which in turn reduces stigma.

6. Provide the same quality of service to all clients regardless of their sexual orientation, practices and behaviour. 
7. Talk to community members about MSM communities and their health care needs.

8. Get to know some MSM individuals to break down stereotypes you may have.

\section{Exercise: Stigma}

Read the case studies below. If you have a partner, role play a counselling session with one person playing the MSM and the other the counsellor.

After you have finished the role play, or if you are doing the case studies on your own, answer the following questions:

1. What types and forms of stigma are present in each case?

2. How do you provide appropriate support for these clients? 


\section{Role Plays}

\section{Role Play Scenario A}

Emeka is a 42-year-old man who lives in Abuja. He studied hotel management but found it difficult to get a job. He used to be the manager of a bar where most of the customers were MSM. His family never accepted his job, and he was rejected and isolated by them. Three years ago, Emeka met a girl with whom he has had two children. He keeps wondering and worrying about his health and whether he should visit a clinic for a check-up. Emekal's biggest fear is that if he is ill, he will need to tell the clinic staff about his sexual behaviour. If word gets out about this, his children may be teased and humiliated in the community.

\section{Role Play Scenario B}

Michael is a very effeminate 27-year-old man who lives in off independence layout, in Enugu. He has engaged in sexual activity with men for the last 10 years. Recently, he went for a health check-up at the local clinic, which included an HIV test. The nurse who tested him shouted at him when she met him and called him a 'homo'. She accused him of immoral behaviour and of disobeying the teachings of his church. Michael is now afraid of seeking health care or testing again for HIV.

\section{Role Play Scenario $C$}

Ahmed is a young married man and the father of two children. He lives in Kaduna, where he teaches English. He has a good relationship with his friends and neighbours. Although he is married, Ahmed sometimes has sex with men. His family does not know about his sexual orientation; however, some people in the neighbourhood have had their suspicions. One day, his family heard a rumour that Ahmed was seen with a group of MSM. Since then, he has faced rejection and threats in the neighbourhood and at school. He finally left his house when he could no longer cope with the situation.

\section{Summary}

- Stigma is defined as an attribute or quality that shames an individual or group of people in the eyes of another individual or group.

- Stigma is a common experience for MARPs such as MSM and has multiple impacts on them.

- Stigma experienced by MSM is known as homophobia. It is fueled by certain religious and cultural beliefs, and is often more harsh for effeminate MSM or those that do not adhere to expected gender norms.

- MSM who are known to be HIV positive may experience the burden of double stigma due to their sexual orientation, behaviour and HIV status.

- External stigma refers to how MSM are treated negatively by others. Some examples include, being ignored, rejection, abuse and violence.

- Internal stigma refers to how MSM feel and act because of external stigma. Some 
examples include, low self-esteem, depression, not seeking medical assistance, social withdrawal and suicide.

- Stigma affects the health and well-being of everyone who is stigmatized and needs to be addressed.

- Appropriate support and counselling can minimize the effects of stigma on MSM well-being. 


\section{Module 4: Sexual Orientation}

\section{Learning objectives}

By the end of this module, you should be able to:

- Explain the term 'sexual orientation' and the factors that influence it.

- Explain the difference between 'sexual orientation' and 'sexual identity' and 'sexual behavior'.

- Engage with common stereotypes regarding sexual orientation.

\section{Introduction}

This module discusses sexual orientation, behavior and their differences.

\section{$\underline{\text { Knowledge section }}$}

\section{What is sexual behavior?}

Sexual behavior includes any form of physical intimacy that involves sexual contact between individuals for the purpose of physical, emotional and sexual enjoyment. Some sexual behavior may also be directed towards reproduction. Healthy sexual behaviours are consensual, nonexploitative, and honest and include actions that protect against unintended pregnancies, and sexually transmitted infections.

\section{Individual exercise}

Give examples of common sexual behaviours

\section{Forms of sexual behavior}

Kissing, oral-anal sex, oral-vaginal sex, anal sex, vaginal sex, masturbation, touching, rubbing, smelling of the vagina, fingering, thigh sex, phone and internet sex, sexual fetishism (sexual preference for particular objects or part of the body such as feet, hair, articles of clothing), spanking, orgies.

Note:

- Sexual behavior includes a wide range of activities that gives the individual sexual 
pleasure

- It does not have to occur between two persons

- It does not have to occur between people of the same sex

- A person's sexual behavior is also not necessarily determined by their biological sex

- People engage in a wide range of sexual activities independent of their sexual orientation, culture, class or age

- People who engage in sexual activities outside of a relationship do so mostly for physical pleasure and not because of emotional attachment.

- People have the right to choose for themselves how to have sex with men and women; no-one has more rights than the other.

\section{What is sexual orientation?}

Sexual orientation refers to the direction or target of a person's sexual feelings. A person's sexual orientation determines the nature of their erotic, romantic and emotional attraction to other people. Basically, it determines whether the person is attracted to persons of the same sex, opposite sex or both sexes. When people are attracted to persons of the opposite sex, they are referred to as 'heterosexuals'. Most people in the society are heterosexuals in their orientation. People attracted to same-sex are called 'homosexuals'. Homosexual men are called gays and homosexual women are called lesbians. They constitute about $10 \%$ of the population. Some people are attracted to both men and women and are called 'bisexuals'. These sexual feelings for members of the same-sex could be expressed in adolescence. They are not 'unnatural' or 'abnormal'.

Sexual preference is a term that insinuates that individuals willfully choose their sexual partnerssuggesting that same sex or bisexual acts are asa result of willful sexual preferences. While this is possible in some circumstances, it is wrong to assume that sexual orientation is a choice and can be changed.

\section{Differences between sexual orientation, sexual identity and sexual behavior}

Sexual identity refers to how a person sees and often portrays him or herself as a sexual being i.e. a person can identify as being Lesbian, Gay, Bisexual, Transgendered and Intersexed (LGBTI). Sexual orientation is about one's feelings of sexual attraction towards another while sexual behaviors are any actions that allow the expression of one's sexual feelings towards another.. A person's social and cultural environment helps shape one's sexual identity. Sexual identities are often informed,but not always, by their sexual orientation.

Sexual minorities: refers to sexual identities which for one reason or the other falls outside the cultural mainstream of a particular society and includes LGBTI (Lesbians, Gays, Bisexual, Trans-(gender, sexual, vestites) and Intersexed) people and MSM. Like marginalized racial, ethnic or religious groups, marginalized sexual minorities are often looked down upon and discriminated against by the dominant group. There is a need for respect ofdifferences where such differences do not infringe on other people's human rights and freedom. 


\section{Group exercise}

What are social factors in the lives of these sexual minorities including MSM that make them vulnerable to getting HIV?

Group 1 - at the individual level

Group 2 - at the community level

Group 3 - health system level

\section{Examples of social factors that could drive HIV vulnerability}

- Stigma and discrimination are multidimensional,

- Resulting in abandonment by family, sexual violence/coercive sex.

- No access to health services and targeted health information

- Young MSM face social exclusion and are also targeted for taunting and bullying by their peers which sometimes results in physical violence.

- Multiple levels of stigma, e.g. being gay and HIV positive

- Some MSM do not see themselves as gay men so they do not see themselves as being vulnerable to getting HIV.

- Driven out of home with no place to live and being forced to look for alternative accommodation may lead to MSM engaging in sex work to survive, intergenerational sex (sugar daddies, aristos), and transactional sex MSM may also find it difficult to find or keep jobs due to stigma and discrimination.

- Fear of rejection by partners may lead to poor negotiation of condom use, which may imply lack of trust to some sexual partners.

- Excessive alcohol and substance abuse results in impaired judgement and sexual risk taking including engaging in unprotected sex and having multiple concurrent sexual partners

- Some MSM are married and have sex with women.

- Poverty

- Imprisonment

- Male-only working/school environment and shared accommodation 


\section{Summary}

- People are not necessarily either gay or lesbian, some men and women who do not consider themselves gay or lesbian may engage in sexual activities with a person of the same sex for physical pleasure without getting emotionally involved.

- These encounters do not necessarily define their sexual orientation.

- MSM and MSW often engage in these activities for various reasons such as imprisonment, male-only working/schooling environment and shared accommodation or sex work.

- Sexual behaviours are any actions that allow expression of one's sexual feelings for example holding hands and kissing, masturbation, and penetrative sexual intercourse.

- MSM have to hide and protect their identity to avoid stigma and discrimination. Once they are exposed, they feel isolated and rejected, hopeless and lose confidence in themselves. This affects their ability to manage their sexual health - they find it hard to access health services, take care of themselves and take less care in negotiating condom use.

- MSM avoid being tested for HIV and getting STIs diagnosed and treated. Since mainstream HIV prevention messages focus on heterosexual sex, they may wrongly believe that penetrative sex between two men holds no sexual risks. They may also believe that unsafe sex represents a small risk compared to fear of rejection by a partner so they avoid using condoms to keep their partners. All these misconceptions increase the risk of contracting HIV.

- In addition to stigma and discrimination, there are other factors putting MSM at risk of getting HIV, including sexual violence, drugs and alcohol.

- Stigma and discrimination towards MSM by families, communities, and service providers increases their risk of contracting HIV. This also increases the risk of HIV spreading in the community, since some MSM are married and also have sex with women. 


\section{Module 5: Sexual practices among MSM}

\section{Learning objectives}

By the end of this module, you should be able to:

- Explain various sexual behaviours practiced by MSM

- Explain different levels of HIV risk associated with some sexual practices by MSM

- Understand that men with women and men with men practice anal sex.

- Recognize different roles during anal sex (insertive/receptive).

- Discuss sexual practice with your clients.

\section{Introduction}

Sexual interactions between men and men and men and women include a range of behaviour. There are many variations and preferences in sexual activity, which carry varying levels of risk for HIV and other STIs. In Nigeria, discussing about sex can be challenging as it is considered a taboo topic. Discussing about anal sex can be even more challenging because it is often surrounded by stigma both from a healthcare provider as well as from a client's point of view. In this module, you will also learn that anal sex is practiced by 'heterosexual' men and women, and by MSM. For women, anal sex is always 'receptive' (she can only receive the penis in her anus). For a man, anal sex can be both 'insertive' (He can insert his penis into the anus of a woman or man) and 'receptive' (he can also receive the penis in his anus).

Healthcare providers are expected to provide services to men who report intercourse with men and women (bisexual), with men only (homosexual), and with women (heterosexual). You will also learn to ask what role a man takes when he reports practicing anal sex and why this is important.

\section{$\underline{\text { Knowledge section }}$}

Common sexual practices include kissing, hugging, mutual masturbation, oral sex, anal stimulation, penile-vaginal penetration, penile-anal penetration, group sex, using sex toys and so on. These practices carry varying levels of risk for HIV and other STIs.

\section{Exercise}

Identify some common sexual practices between men and women and the HIV/STIs risk levels 
Table showing common sexual practices between men and women and HIV/STI risk levels

\begin{tabular}{|c|c|c|c|}
\hline Sexual practice & $\begin{array}{l}\text { Between man \& } \\
\text { woman }(M, W)\end{array}$ & $\begin{array}{l}\text { Between man \& man } \\
(M, M)\end{array}$ & $\begin{array}{l}\text { HIV/STI risk level } \\
\text { (low, medium, high) }\end{array}$ \\
\hline Kissing & $M-W$ & $M-M$ & Low risk \\
\hline Hugging & $M-W$ & $M-M$ & Low risk \\
\hline Mutual masturbation & $M-W$ & $M-M$ & Low risk \\
\hline Oral sex & $W-M, M-W$ & $M-M$ & Medium risk \\
\hline Anal stimulation & $M-W, W-M$ & $M-M$ & Medium risk \\
\hline $\begin{array}{l}\text { Unprotected vaginal } \\
\text { intercourse }\end{array}$ & $M-W$ & - & High risk \\
\hline $\begin{array}{l}\text { Unprotected anal } \\
\text { intercourse }\end{array}$ & $M-W$ & $M-M$ & High risk \\
\hline $\begin{array}{l}\text { Unprotected sexual } \\
\text { intercourse with a } \\
\text { group of people }\end{array}$ & $M-W$ & $M-M$ & High risk \\
\hline
\end{tabular}

\section{What is anal sex?}

Anal sex is a sexual act that involves the insertion of the penis into the anus. This is a common sexual behaviour among MSM but it is also practiced between men and women.

When a man engages in anal sex he can engage in either:

- Insertive anal sex $\square$ - which occurs when a man uses his penis to penetrate his partner. The insertive partner is referred to as the 'top', or the active partner.

- Receptive anal sex $\square$ - which occurs when a man is penetrated by his partner's penis. The receptive partner is called a 'bottom' or the passive partner.

MSM who engage in anal sex may prefer to engage in only one type of anal sex, insertive or receptive, or to engage in both roles, 'versatile'.

\section{Anal sex practice among heterosexual men and women}

Anal intercourse has been one of the most stigmatized of heterosexual sexual behaviours, perhaps because of its association with male homosexuality. In Nigeria and Africa, very little is known about how common anal sex is among heterosexual men and women. While questions about anal sex in the general population are rarely asked, anal sex practice among female sex workers (FSWs) in Africa has been assessed in some surveys. Anal sex is not exclusively practiced by MSM. MSM exist in Africa as anywhere else, and they are among those with highest risk of contracting HIV and are also unaware that HIV can be transmitted anally. It seems probable that heterosexual men and women also know equally little about anal sex and the risk of STI and HIV transmission during this activity - this is simply because health care providers do not ask them about it. The difference in risk of HIV infection through anal sex as opposed to vaginal sex has to do with differences between the anus and 
the vagina. The anus continues to the rectum and has many specialized muscles. The lining of the anus and rectum is thinner than that of the vagina - making it easier for bleeding and damage to occur during sex.

Table showing the differences between penile-anal and penile-vaginal sex.

\begin{tabular}{|l|l|}
\hline Penile - Anal Sex & Penile - Vaginal Sex \\
\hline No natural lubrication in anus & $\begin{array}{l}\text { Vagina produces natural lubrication when } \\
\text { sexually aroused }\end{array}$ \\
\hline Anus has limited elasticity & Vagina has elasticity and stretches \\
\hline $\begin{array}{l}\text { Colon and rectum only a single layer of } \\
\text { epithelia cells i.e. one cell thick }\end{array}$ & Vagina much thicker epithelial layer \\
\hline $\begin{array}{l}\text { Tears easily with no lubrication } \\
\text { Presence of faecal matter possible } \\
\text { (containing bacteria) }\end{array}$ & $\begin{array}{l}\text { Vagina doesn't tear as easily, and is more } \\
\text { robust }\end{array}$ \\
\hline $\begin{array}{l}\text { Many inflammatory cells (CD4 receptors) } \\
\text { under surface in rectum }\end{array}$ & $\begin{array}{l}\text { Fewer CD4 receptor cells in vagina than } \\
\text { rectum }\end{array}$ \\
\hline
\end{tabular}

Different sex acts carry different risk for HIV infection. In men, unprotected receptive anal sex is 10 times more risky than engaging in unprotected vaginal sex (Figure 1). For a woman, engaging in unprotected (receptive) anal sex is five times more risky than engaging in unprotected vaginal sex (Figure 2). Of note, the risk of HIV infection during receptive anal sex is the same whether you are a man or a woman.

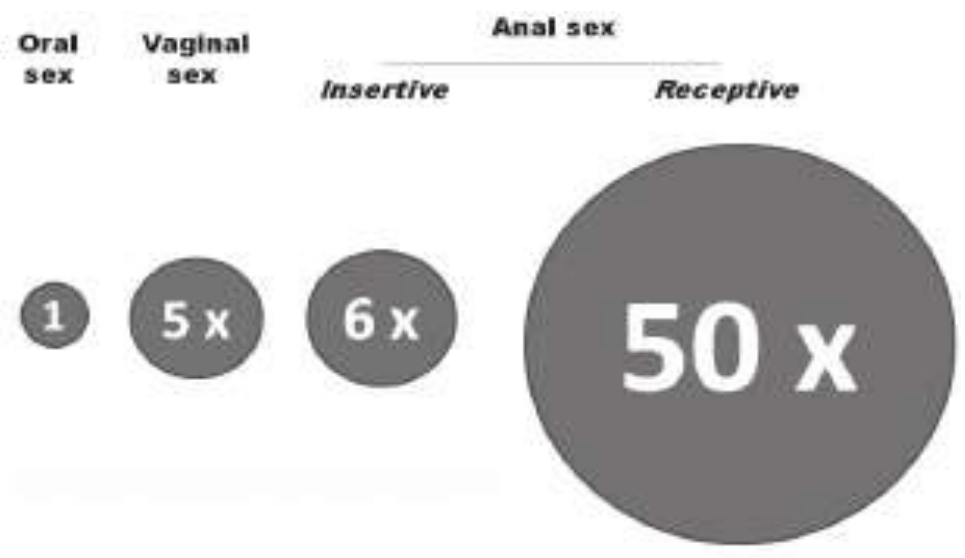

Figure 1: Male risk for HIV during different sex acts (Smith et al. (2005)) 


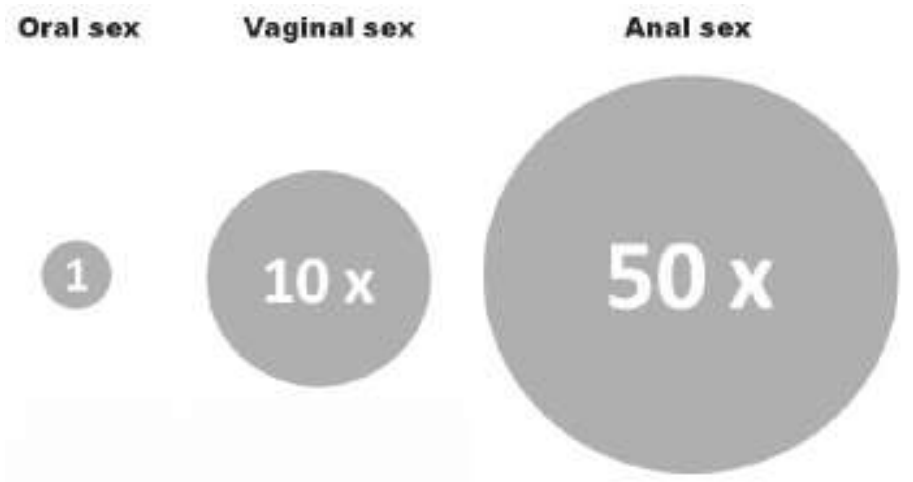

Figure 2: Female risk for HIV during different sex acts (Smith et al. (2005))

As we reflect upon our own attitude towards anal sex practice, let us read the case studies. 


\section{Case Study 1}

Fatima is 19 years old. She has come for HCT at your facility because she will be getting married in a few weeks to a man who is 29 years older. She is a bit nervous for the test and says that she is a virgin. She wants you to do the test 'for information' and, upon further prompting, because she is not certain about her future husband.

You are in doubt. You wonder if you should ask her to come back with her husband-to-be, or if she has another concern. Is she sexually active already? How you can introduce the topic of anal sex without 'losing contact with her' and find out more about the real reason of her visit?

This case study illustrates that some women have avoided getting pregnant or losing their virginity by engaging in anal intercourse. Young girls in Christian, Islamic and traditional societies throughout Africa practice anal sex in order to protect their vaginal or 'technical' virginity. In many regions of African the traditional coming-of-age, ritual of some "virginity testing' is practiced; young girls are examined before marriage to ensure that their hymen is intact. Discovery of a ruptured hymen brings shame to a girl and her family, and can jeopardize her eligibility for marriage. Because of the high value placed on virginity and hymen maintenance (a falsity as the hymen can be ruptured in non-sexual activity such as tampon use or physical exercise) young people choose to have oral and anal sex instead.

\section{Case Study 2}

Jean is a 19-year-old male sex worker who works mostly around bars in the city centre. He is not very proud of his work but feels he has no choice as he did not go to secondary school and has no training or professional skill. Tonight he is hungry and has only enough money for his fare home. Jean is quite small and not very physically strong.

Festus is 42, married with three children and a successful businessman. He occasionally comes into the city at night to pay for sex with men and sometimes street boys. He does not consider himself gay. He enjoys sex with men because he can 'be rough'. Festus knows about HIV and STIs but assumes that anal sex is safe. Tonight he wants rough sex and approaches Jean.

\section{Points to ponder}

In both case studies above, Fatima, Jean and Festus may have anal sex for the following reasons: preserving virginity, avoiding pregnancy, earning some extra money, and enjoying some rougher insertive anal sex.

Homosexuality was not mentioned in these cases. It may be possible that if you asked Jean or Festus if they would have homosexual contact, they would answer in the negative.

Do you think about anal sex as an act that is practiced among homosexuals only?

Asking questions about anal sex of a man or a woman is as important as asking an MSM about anal sex. However, when a man reports anal sex you need to ask if he does it with women or men, or with both. If he has sex with men, you need to ask about sexual role taking. 


\section{Exercise: Agree/Disagree}

\section{Facilitator tips}

1. Make sure there is enough space for participants to walk freely from one end of the room to the other.

2. Place a large piece of paper headed 'Agree' and another with 'Disagree' on the wall at each end of the room.

3. Tell participants that you will read out a statement and they should then go to the end of the room that best represents their response. If they are not sure, they should stand in the middle of the room, or in the direction of the answer that most describes their response

4. After you have called out the first statement and participants have placed themselves accordingly, ask in turn for a volunteer from each end of the room to explain to the group why they are standing where they are. Ask others to share their response before moving on to the next statement.

5. Allow debate - without arguments arising - write down key words and comments that come up to be discussed and explained after the activity.

6. Afterwards, ask participants:

a. What did you learn from the activity?

b. What did you learn about yourself?

Do you agree or disagree with the following statements?

1. Anal sex is a natural behavior.

2. There should be no laws against anal sex

3. Anal sex goes against religion

4. Anal sex was brought to Africa from the West

5. It is not possible for a woman to enjoy anal sex

\section{Discussing anal sex with your client}

During pre- HIV counseling and testing session, a client may be asked about the number of sex partners he has had in a certain period. For instance, 'In the past month, how many partners have you had?' With that one question and the answer to it, however, a counsellor will not know what 'exposure' took place (i.e. what kind of sex?), and counselling on possible risk behaviours will not be sufficiently tailored to the behaviour of that client, therefore other questions are required to gain more information. For example, Was there oral, anal or vaginal sex? Was there penetrative sex with the regular partner and oral sex with the one-off partner? Which sex act was protected? Were condoms used the first round and not in the second round?

Health care providers are trained to ask these questions of clients but they may not be trained to ask the same questions about anal sex because of the stigma surrounding it and the misconception that it is practiced by MSM only. Many health care providers and counsellors feel very uncomfortable and embarrassed to ask about anal sex. By gaining more information about anal sex and about the risks that it poses for HIV transmission, health care providers can grow to understand the importance of discussing it with their clients. Men can practice anal sex in different positions and thus counselors must ask clear questions in order to gain understanding of their clients' behaviour and risk taking. 
Below are helpful questions that can be asked by a counsellor or clinician to gain a deeper understanding of their clients' behaviour:

- Have you ever practiced anal sex?

- Have you practiced anal sex during the last year (or shorter period)?

- Did you practice anal sex with a woman, a man, or with both?

- What role do you play during anal sex? Were you the receptive partner, the insertive partner, or both?

- Did you use a condom the last time you had insertive/receptive anal sex?

- What type of lubrication did you use for anal sex?

These questions can be asked along with other standard sexual behavior questions. Sometimes, clients will understand your question better when you use language that is less formal, for instance: Are you usually 'top', 'bottom', or 'both'?

\section{Anal sex and HIV testing}

At first enquiry, clients very commonly deny engaging in anal intercourse, and usually it is only at the second or third clinical visit that they acknowledge and discuss this aspect of their sexuality. Unfortunately, there is still little health care worker training that focuses on supporting discussing anal sex practices with clients even though unprotected receptive anal sex is the most efficient method of the sexual transmission of HIV. Health care providers have an opportunity to exchange such information when they first contact the client before offering an HIV test. Central to counselling training is the understanding that HIV can be transmitted between adults when contact is made between the penis and the vagina. Hence, HIV prevention programmes and the messages that only focus on 'abstaining from sex', 'being faithful to one partner', and 'using condoms each time you have sex' miss out on an important and very risky route of HIV transmission, i.e. anal sex.

\section{Exercise: HIV testing and anal sex questioning}

Recall the last time that you conducted HIV counselling and testing for a client. This could have been a voluntary test at a HCT clinic, a diagnostic lab test, or a research-initiated test (purposefully offered in view of participation in a research protocol).

Reflect on the moment when you approached the topic of HIV transmission and HIV prevention. You will have said something like, 'I am going to ask some questions about your sexual partners and about your understanding of HIV transmission'. Now reflect on the last time you counseled and tested an adult for HIV.

Did you ask about anal sex practice?

If you did: recall your question(s) and what the client's response was.

If you did not: try to recall the reason why you did not. 


\section{Summary}

- Sexual interactions between men and women include a range of practices.

- Different sexual practices carry different levels of risk for HIV

- Counsellors and clinicians should know the risks associated with different sexual behaviours and advise clients on how to reduce their risk of becoming infected with HIV and other STIs, or transmitting HIV and STIs

- Asking about, and counselling on sexual behaviours is an important part of HIV and STI prevention.

- Counselling sessions are opportunities to enquire about and provide information about the risks of different sexual practices including anal sex.

- Anal sexual practices occur in Africa between men and women, and between men.

- MSM may take either or both receptive and insertive anal sex roles. 


\section{Module 6: HIV and sexually transmitted infections (STIs)}

\section{Learning Outcomes}

By the end of this module, you should be able to

- List the common STIs

- List common symptoms of STIs

- Describe how to ask clients about symptoms of STIs

- Explain how STIs are spread

- Describe how to explain to clients what they should do if they have or suspect an STI

- Explain the link between HIV infection and STIs

\section{Introduction}

Sexually transmitted infections (STIs) are a group of infections that can be passed between individuals during unprotected sexual activity. Health care providers may find it difficult to provide treatment and care services to MSM due to fear and discrimination. Health care workers have an obligation to provide healthcare services to all irrespective of their sexual orientation or practices.MSM in Nigeria carry a high burden of sexually transmitted infections as is evidenced in various studies among these populations.

Currently, existing STI treatment guidelines in Nigeria are insufficient for MSM, as they do not take into consideration receptive anal intercourse and do not suggest treatment for certain infections that may specifically affect MSM communities. Often, health care providers' such as counselors or nurses are the first point of contact for many MSM in the health care setting. They have a good opportunity to assist in referring clients with a potential STI to a health care professional; therefore, it is crucial for all health care workers to know about the STIs that are common in MSM.

This module will focus on the basic facts of common STIs that may be encountered when working with MSM. While this knowledge will not replace that of a trained medical professional, it can assist in encouraging participants to seek out this type of medical assessment.

\section{$\underline{\text { Knowledge section }}$}

\section{What are STIs?}

STIs are infections that may be caused by bacteria or viruses. Most are spread through bodily fluids (semen, ejaculate fluid/pre-cum, blood) and others by direct contact (touching skin, open sores). Among MSM, these infections can be spread through oral, penile-anal and oro-anal sex.

\section{What are common symptoms of STIs?}

The following can be potential signs of STIs. Should a client report any of these symptoms, they 
should be referred for a medical follow-up:

- Sores on the vagina, penis, testicles, anus and surrounding area

- Burning urination

- White discharge (pus) from the vagina, penis or anus

- Painful testicles (balls)

- Swollen glands on the inside of the leg

- Growth on the vagina, penis, testicles, anus and surrounding area

- Pain or bleeding with defecation (bowel movements)

- New-onset painful receptive anal or vaginal intercourse

- Itchy genital area, vagina, penis or anus

\section{How are STIs contracted?}

STIs are contracted through the exchange of bodily fluids (blood, semen, etc.) or from direct contact during oral, anal, vaginal, oro-vaginal, or oro-anal sex. Unprotected receptive anal sex carries the highest risk for STIs. Unprotected penetrative anal sex is also high risk for infections that can occur in the penis or the anus.

During oral sex, infection can be spread between the penis of the insertive partner and the throat of the receptive partner. During oro-anal sex, infections can be spread between the anus of the receptive partner and the mouth of the person giving oro-anal sex. Lastly, infection can also be spread by directly touching open sores (ulcers).

\section{Is there a link between HIV and STIs?}

People who are HIV infected and have an STI spread the virus more easily to other people and people with STIs can contract HIV more easily. This is because STIs causes swelling and increased blood flow to infected areas, and infections that cause sores (or ulcers) break the skin's surface. The increased blood flow and broken skin make it easier for HIV to enter/leave the body.

\section{Human immunodeficiency virus (HIV)}

HIV is a virus that is spread through bodily fluids, affects the human immune system and causes AIDS. Receptive unprotected anal sex carries the highest risk of becoming infected with HIV. Unprotected penetrative penile-vaginal, penile-anal sex also carries a high risk of contracting HIV. Oral-penile sex and oro-anal sex also carry some risk of HIV infection, but this risk is much lower. The chance of getting HIV is higher if there are cuts or sores in the mouth or around the vagina, penis and anus.

In HIV-positive men, ejaculation fluid (semen, cum) and blood carry the highest number of viruses. However, pre-ejaculate (pre-cum) may also contain HIV. Removing the penis before ejaculation during vaginal, oral or anal sex still carries a risk of HIV transmission. All sexually active individuals should be offered HIV testing every six months to a year. For people who have 
many risky exposures (unprotected anal intercourse, multiple sexual partners, concurrent partners, and transactional sex) HIV testing should be done more regularly every three to six months. The spread of HIV can be greatly reduced if HIV diagnosis is made early, since most infections are spread from individuals who are in the early stages of infection and are often not aware that they are spreading it to their sexual partners

\section{What STIs are common among MARPs?}

The following STIs can be common in MSM: HIV, syphilis, gonorrhoea, chlamydia, herpes, viral hepatitis and warts (caused by a virus called the human papilloma virus or HPV).

Table showing common STIs among MSM

\begin{tabular}{|c|c|c|c|c|c|}
\hline & CHLAMYDIA & GONORRHEA & $\begin{array}{l}\text { HUMAN } \\
\text { PAPILLOMAVIRUS } \\
\text { (HPV OR GENITAL } \\
\text { WARTS) }\end{array}$ & $\begin{array}{l}\text { GENITAL } \\
\text { HERPES }\end{array}$ & SYPHILIS \\
\hline What is it? & $\begin{array}{l}\text { A common } \\
\text { bacterial infection } \\
\text { of the genital area. }\end{array}$ & $\begin{array}{l}\text { A bacterial } \\
\text { infection of the } \\
\text { genital area. }\end{array}$ & $\begin{array}{l}\text { A viral infection with } \\
\text { more than } 100 \text { different } \\
\text { types that affect the } \\
\text { genital area. }\end{array}$ & $\begin{array}{l}\text { A viral infection } \\
\text { of the genital } \\
\text { area. It can also } \\
\text { affect the area } \\
\text { around the } \\
\text { mouth. }\end{array}$ & $\begin{array}{l}\text { An infection } \\
\text { caused by bacteria } \\
\text { that can spread } \\
\text { throughout the } \\
\text { body }\end{array}$ \\
\hline $\begin{array}{l}\text { How do I get } \\
\text { infected? }\end{array}$ & $\begin{array}{l}\text { Through } \\
\text { unprotected oral, } \\
\text { anal, or vaginal } \\
\text { sexual intercourse } \\
\text { with an infected } \\
\text { person. }\end{array}$ & $\begin{array}{l}\text { Through } \\
\text { unprotected oral, } \\
\text { anal, or vaginal } \\
\text { sexual intercourse } \\
\text { with an infected } \\
\text { person. }\end{array}$ & $\begin{array}{l}\text { Through unprotected } \\
\text { oral, anal, or vaginal } \\
\text { sexual intercourse and } \\
\text { skin-to-skin contact } \\
\text { with an infected } \\
\text { person. }\end{array}$ & $\begin{array}{l}\text { Through } \\
\text { unprotected oral, } \\
\text { anal, or vaginal } \\
\text { sexual } \\
\text { intercourse and } \\
\text { skin-to-skin } \\
\text { contact with an } \\
\text { infected person. }\end{array}$ & $\begin{array}{l}\text { Through } \\
\text { unprotected oral, } \\
\text { anal, or vaginal } \\
\text { sexual intercourse } \\
\text { and kissing an } \\
\text { infected person } \\
\text { who has lesions on } \\
\text { the mouth. }\end{array}$ \\
\hline You can NOT & $\begin{array}{l}\text { Get chlamydia } \\
\text { from casual } \\
\text { contact such as } \\
\text { hugging, kissing } \\
\text { or sharing food } \\
\text { and drink. }\end{array}$ & $\begin{array}{l}\text { Get gonorrhea } \\
\text { from casual } \\
\text { contact such as } \\
\text { hugging, kissing } \\
\text { or sharing food } \\
\text { and drink. }\end{array}$ & & & $\begin{array}{l}\text { Get syphilis from } \\
\text { toilet seats and } \\
\text { door knobs. }\end{array}$ \\
\hline Symptoms & $\begin{array}{l}\text { There are no } \\
\text { symptoms in most } \\
\text { women and men } \\
\text { who are infected. } \\
\text { Men develop } \\
\text { discharge or pain } \\
\text { during urination 1- } \\
3 \text { weeks after } \\
\text { having sexual } \\
\text { intercourse with } \\
\text { an infected } \\
\text { partner. }\end{array}$ & $\begin{array}{l}\text { Most infected } \\
\text { people do not have } \\
\text { any symptoms. } \\
\text { For those who do, } \\
\text { it can cause a } \\
\text { burning sensation } \\
\text { while urinating, } \\
\text { greenish or } \\
\text { yellowish penile } \\
\text { discharge, } 2-10 \\
\text { days after sexual } \\
\text { intercourse with } \\
\text { an infected person. }\end{array}$ & $\begin{array}{l}\text { Most people infected } \\
\text { have no symptoms. But } \\
\text { some HPV types can } \\
\text { cause genital warts } \\
\text { (small growths in and } \\
\text { around the genitals; } \\
\text { vagina, penis, testicles } \\
\text { and anus) if they do } \\
\text { occur, warts may } \\
\text { appear within weeks or } \\
\text { months of infection. }\end{array}$ & $\begin{array}{l}\text { Most people have } \\
\text { no symptoms. } \\
\text { Herpes } 1 \text { usually } \\
\text { causes cold sores } \\
\text { and fever blisters } \\
\text { on the mouth; } \\
\text { Herpes } 2 \text { is } \\
\text { usually the cause } \\
\text { of genital sores } \\
\text { or blisters. Both } \\
\text { viruses can cause } \\
\text { an outbreak of } \\
\text { painful red sores } \\
\text { around the mouth } \\
\text { and genital areas. } \\
\text { It can also lead to }\end{array}$ & $\begin{array}{l}\text { In the first phase, } \\
\text { a single sore } \\
\text { (Chancre) may } \\
\text { appear on the } \\
\text { genitals or mouth } \\
2 \text { weeks after } \\
\text { infection for as } \\
\text { long as } 3 \text { months. } \\
\text { The chancre can } \\
\text { be present for } 1- \\
5 \text { weeks. Often } \\
\text { there are no } \\
\text { noticeable } \\
\text { symptoms but the } \\
\text { person is very } \\
\text { infectious. In the }\end{array}$ \\
\hline
\end{tabular}




\begin{tabular}{|c|c|c|c|c|c|}
\hline & & & & $\begin{array}{l}\text { flu-like } \\
\text { symptoms; fever, } \\
\text { headaches and } \\
\text { swollen glands } \\
\text { during the first } \\
\text { outbreak. } \\
\text { Symptoms } \\
\text { usually appear } \\
\text { within } 2 \text { weeks } \\
\text { of infection. The } \\
\text { virus stays in the } \\
\text { body forever and } \\
\text { may cause } \\
\text { recurrent } \\
\text { outbreaks. }\end{array}$ & $\begin{array}{l}\text { second phase, up } \\
\text { to } 6 \text { months after } \\
\text { the first sore has } \\
\text { disappeared, a } \\
\text { variety of } \\
\text { symptoms appear } \\
\text { including a rash } \\
\text { (often on the } \\
\text { palms of the hand } \\
\text { or soles of the } \\
\text { feet, but also on } \\
\text { other body parts. } \\
\text { Tertiary syphilis } \\
\text { occurs many years } \\
\text { after infection and } \\
\text { attacks the } \\
\text { nervous system } \\
\text { causing, stroke, } \\
\text { brain damage, } \\
\text { blindness and } \\
\text { hearing loss and } \\
\text { also leads to heart } \\
\text { attack and death. }\end{array}$ \\
\hline Test Required & A urine test & A urine test & $\begin{array}{l}\text { Blood test or swab of } \\
\text { infected area. }\end{array}$ & $\begin{array}{l}\text { Blood test or } \\
\text { swab of infected } \\
\text { area. }\end{array}$ & Blood test \\
\hline $\begin{array}{l}\text { How can I } \\
\text { prevent it? }\end{array}$ & $\begin{array}{l}\text { Abstinence from } \\
\text { sexual intercourse. } \\
\text { Be in a mutually } \\
\text { monogamous } \\
\text { relationship or } \\
\text { reduce the number } \\
\text { of sexual partners. } \\
\text { Correct and } \\
\text { consistent condom } \\
\text { use will usually } \\
\text { prevent infection. }\end{array}$ & $\begin{array}{l}\text { Abstinence from } \\
\text { sexual intercourse. } \\
\text { Be in a mutually } \\
\text { monogamous } \\
\text { relationship or } \\
\text { reduce the number } \\
\text { of sexual partners. } \\
\text { Correct and } \\
\text { consistent condom } \\
\text { use will usually } \\
\text { prevent infection. }\end{array}$ & $\begin{array}{l}\text { Abstinence from sexual } \\
\text { intercourse. Be in a } \\
\text { mutually monogamous } \\
\text { relationship with one } \\
\text { partner. Limit the } \\
\text { number of sex partners. } \\
\text { Correct and consistent } \\
\text { condom use can reduce } \\
\text { the risk of infection } \\
\text { although the infection } \\
\text { can affect areas that are } \\
\text { not protected by } \\
\text { condoms. }\end{array}$ & $\begin{array}{l}\text { Abstinence from } \\
\text { sexual } \\
\text { intercourse. Be } \\
\text { in a mutually } \\
\text { monogamous } \\
\text { relationship with } \\
\text { a partner who has } \\
\text { been tested and is } \\
\text { known to be } \\
\text { uninfected. } \\
\text { Correct and } \\
\text { consistent } \\
\text { condom use can } \\
\text { reduce the risk of } \\
\text { infection } \\
\text { although the } \\
\text { infection can } \\
\text { affect areas that } \\
\text { are not protected } \\
\text { by condoms. } \\
\text { Persons with } \\
\text { herpes infection } \\
\text { should abstain } \\
\text { from sexual } \\
\text { activity with } \\
\text { uninfected } \\
\text { partners when } \\
\text { lesions or other } \\
\text { symptoms are } \\
\text { present }\end{array}$ & $\begin{array}{l}\text { Abstinence from } \\
\text { sexual intercourse. } \\
\text { Be in a } \\
\text { monogamous } \\
\text { relationship or } \\
\text { reduce the number } \\
\text { of sexual partners. } \\
\text { Correct and } \\
\text { consistent condom } \\
\text { use will usually } \\
\text { prevent infection. } \\
\text { Regular screening } \\
\text { for this infection } \\
\text { will ensure you } \\
\text { always know your } \\
\text { syphilis status and } \\
\text { prevent you from } \\
\text { spreading it to } \\
\text { your sex partner. }\end{array}$ \\
\hline Treatment & $\begin{array}{l}\text { Oral antibiotics } \\
\text { cure the infection. } \\
\text { Both partners must } \\
\text { be treated at the } \\
\text { same time to } \\
\text { prevent passing }\end{array}$ & $\begin{array}{l}\text { Oral antibiotics } \\
\text { cure the infection. } \\
\text { Both partners must } \\
\text { be treated at the } \\
\text { same time to } \\
\text { prevent passing }\end{array}$ & $\begin{array}{l}\text { There is no cure for the } \\
\text { virus (HPV), but warts } \\
\text { can be treated through } \\
\text { topical medicines or } \\
\text { methods to freeze } \\
\text { them. Even with such }\end{array}$ & $\begin{array}{l}\text { There is no cure } \\
\text { but medications } \\
\text { can help reduce } \\
\text { the pain and } \\
\text { itching as well as } \\
\text { the frequency of }\end{array}$ & $\begin{array}{l}\text { Antibiotics can } \\
\text { cure the infection } \\
\text { if it is diagnosed } \\
\text { early. But } \\
\text { medication can't } \\
\text { undo the damage }\end{array}$ \\
\hline
\end{tabular}




\begin{tabular}{|l|l|l|l|l|l|}
\hline & $\begin{array}{l}\text { the infection back } \\
\text { and forth, and both } \\
\text { partners need to } \\
\text { abstain from } \\
\text { unprotected sexual } \\
\text { intercourse until } \\
\text { the infection is } \\
\text { gone. }\end{array}$ & $\begin{array}{l}\text { the infection back } \\
\text { and forth, and both } \\
\text { partners need to } \\
\text { abstain from } \\
\text { unprotected sexual } \\
\text { intercourse until } \\
\text { the infection is } \\
\text { gone. }\end{array}$ & $\begin{array}{l}\text { treatments, the virus } \\
\text { can still be present and } \\
\text { can cause } \\
\text { reoccurrences. It is not } \\
\text { known how long a } \\
\text { person remains } \\
\text { contagious after warts } \\
\text { are treated. }\end{array}$ & $\begin{array}{l}\text { recurrent } \\
\text { outbreaks. Daily } \\
\text { medications can } \\
\text { also reduce the } \\
\text { likelihood of } \\
\text { spreading } \\
\text { infection to sex } \\
\text { partners. }\end{array}$ & $\begin{array}{l}\begin{array}{l}\text { already done. Both } \\
\text { partners must be } \\
\text { treated at the same } \\
\text { time. }\end{array} \\
\end{array}$ \\
& & & & \\
\end{tabular}

\section{How can you ask about STI symptoms?}

Asking about STIs should be standard practice during HIV counselling and testing sessions, and during medical history taking. Speaking with a client about STIs and the symptoms associated with them can sometimes be difficult because the client may be embarrassed to speak openly about them. This challenging barrier can often be overcome by explaining to the client that STIs are very common and many are easily treatable. Below are some questions that are non-specific but may help to identify an STI. MSM with any of these symptoms or other symptoms associated with the vagina, penis, anus and genital area should be referred to a health care professional for management.

- Have you noticed any sores on your private parts (vagina, penis, anus and surrounding area)?

- Do you find it uncomfortable to pass urine?

- Do you have any burning sensations when urinating?

- Have you noticed clear or white fluid on the tip of your penis that is not semen?

- Are you experiencing any pain in your testicles that is new?

- Is receptive anal sex more painful or uncomfortable than before?

- Have you noticed any blood when having a bowel movement?

- Have you noticed any white fluid or pus leaking from your anus or vagina?

- Do you have any irritation or itchiness in your private parts that is new?

\section{What should health care providers do if they suspect a client may have an STI?}

Any client with symptoms of an STI should be offered HIV testing, and needs to be referred for medical evaluation. Clients who report symptoms of an STI should be made aware of the problems and risks caused by them. Their sexual partners also need to be referred for medical review, even if they do not have any symptoms. 


\section{Group Exercise 1}

Referring to the sexual practices table, from Module $X$, go through all the sexual activities written, marking each with an ' $L$ ' (low risk), ' $M$ ' (medium risk) or ' $H$ ' (high risk) for spreading HIV and STIs.

Referring to the table, discuss which STIs could be spread through each activity.

\section{Group Exercise 2}

Instructions (30 minutes)

Hand out copies of the case studies below. Ask the participants to discuss them in pairs. Allow each person 10 minutes to act as the client and 10 minutes as the counsellor for one of him or her. Allow 10 minutes to discuss difficult issues, and answer questions in a group.

\section{Case Study 1}

Abdul, a 40-year-old father of two, comes to the clinic for an HIV test. He tells you that for the last three days he has had a burning sensation while urinating, and noticed white fluid on the tip of his penis when he woke up that morning. He tells you that he had unprotected sex with a sex worker 3 weeks ago when he was in Abuja on a business trip.

Explain to Abdul what could be causing the burning urine and the white fluid on the tip of his penis.

Counsel Abdul on what he should do. Include advice about referral, treatment, prevention and risk of HIV infection.

\section{Summary}

- STIs, including HIV, are common among MSM.

- Early identification and treatment of STIs can minimize the spread and effects of STIs.

- HIV is transmitted more easily when one/both partners have an STI, open sores or wounds, or broken skin.

- As a counselor you are able to inform clients about the risks associated with different sexual behaviours/practices.

- A health care professional should assess all suspected or confirmed symptoms of an STI.

- Screening for common STIs should be included in all HIV counselling sessions. 


\section{Module 7: Condom and Lubricant Use}

\section{Learning outcomes}

By the end of this module, you should be able to:

- Highlight the role of condoms for preventing HIV and STIs

- Explain the main differences between male and female condoms

- Discuss the difference between oil-based and water-based lubricants

- Tailor condom promotion messages to take into account the range of sexual behaviors of MSM.

\section{Introduction}

In this module, you will learn about male and female condoms, and understand their key role in preventing HIV and STIs. This module equips you with the necessary knowledge and skills to incorporate practical advice on correct, consistent condom and lubricant use, identify common errors in condom use, and tailor your prevention messages to the sexual behaviours of MSM.

\section{$\underline{\text { Knowledge section }}$}

\section{Male and female condoms}

A condom is a protective sheath used during anal or vaginal sexual intercourse. It creates a physical 'barrier' between the genitals and sexual fluids of two partners engaging in intercourse. It can be used for contraception, and/or HIV and STI prevention. There are two main types of condoms - 'male' condoms and 'female' condoms.

Male condoms are usually made out of latex (rubber). Female condoms are usually made out of polyurethane (a thin strong plastic) or Nitrile. Male condoms made out of polyurethane also exist (but are not widely available) - these are useful for those who have latex allergies.

Currently, the female condom is approved for vaginal use only - that is why it is called the 'female condom'. However, 'female condoms' can also be used for anal sex, and research evidence has shown that some MSM use the female condom for HIV/STI protection.

\section{Group Exercise}

Each participant should mention a condom brand name that they know 
Table showing similarities and differences between male and female condoms

\begin{tabular}{|l|l|}
\hline Male Condom & Female Condom \\
\hline Latex (Rubber) & Polyurethane, Nitrile (Plastic) \\
\hline $\begin{array}{l}\text { Water-based lubricants only } \\
\text { e.g. K-Y Jelly®, Lubrica, Assegai }\end{array}$ & Any lubricant, preferably water-based. \\
\hline Can break if not used correctly & Does not break easily \\
\hline $\begin{array}{l}\text { Some men find it too tight/ } \\
\text { Restrictive }\end{array}$ & Not tight on penis \\
\hline $\begin{array}{l}\text { Must be put on/taken off the erect } \\
\text { penis immediately before/after } \\
\text { penetration }\end{array}$ & $\begin{array}{l}\text { Can be inserted before penetration } \\
\text { and left in for a longer time }\end{array}$ \\
\hline Does not conduct heat & Warms up to body temperature \\
\hline $\begin{array}{l}\text { Must be worn on the penis (insertive } \\
\text { partner) }\end{array}$ & $\begin{array}{l}\text { Can be inserted into anus (receptive } \\
\text { partner) or used over the penis } \\
\text { (insertive partner) }\end{array}$ \\
\hline
\end{tabular}

\section{How well do condoms work?}

When used correctly and for all sex acts, condoms are 80-95\% effective at preventing HIV and STIs. However, individuals do not use condoms correctly or consistently resulting in potential exposure to HIV/STIs.

Male and female condoms are manufactured according to strict quality standards and are tested for strength, leakage, lubrication, proper packaging and labeling.

\section{Instructions for correct male condom use}

1. Store condoms in a place away from heat and humidity. Check the expiration date on the package. Check that the package is not damage and has no holes by feeling the air in it.

2. Do not rip or puncture the condom when opening the package. Open it with the fingers, NOT with teeth, scissors, a knife or anything sharp.

3. Check that the condom is not dry.

4. Make sure the tip of the condom is the right way round - the lubricated side should be on the outside, and the condom should roll down easily.

5. Pinch the tip (teat) of the condom with one hand. This removes the air and makes space to hold the semen.

6. Place the condom on the erect penis and unroll it to the base of the penis with the other hand, while still pinching the tip of the condom.

7. Smooth out any air bubbles.

8. Add a water-based lubricant (e.g. K-Y Jelly®) to the outside of the condom if necessary. Do not use oil-based lubricants.

9. After ejaculation, hold the condom at the base of the penis and pull it off before the penis softens.

10. Remove the condom, taking care not to spill any semen.

11. Make a knot in the condom and dispose of it appropriately out of the reach of children.

12. Use a new condom for each new act of intercourse.

13. If the condom breaks or slips during intercourse STOP, remove it and put on a new one. 


\section{Some common condom use errors}

- Putting on the condom halfway through sex, i.e. after sexual contact has already occurred.

- Removing the condom and resuming intercourse without one.

- Using a condom for the first round of sex, but not for the second or third round.

- Failing to pinch the tip of the condom (to remove the air) when putting it on.

- Withdrawing after the penis has softened.

- Failure to add lubricant, especially during anal sex.

- Use of oil-based lubricants (e.g. lotion, vegetable oil, Vaseline) that can damage the latex.

- Lengthy or vigorous sex.

- Engaging in sexual positions that may increase the likelihood of slippage.

- Putting on two male condoms at the same time.

\section{Instructions for correct female condom use}

Method 1: Use by receptive partner

1. Check the expiry date.

2. Find the arrow on the packaging and tear downwards carefully to avoid tearing.

3. At the closed end of the condom, squeeze the flexible inner ring between your thumb and second or middle finger so that the ring becomes long and narrow.

4. Gently insert the inner ring into the vagina or anus.

(Some users prefer to take out the inner ring before insertion to make the condom more comfortable)

Push it far inside. For anal sex, when inserted properly, about one inch of the outer ring will hang out of the anus.

5. Leave the outer ring on the outside of the body.

6. Add lubricant to the inside of the female condom or on the penis if needed.

7. Guide the penis inside the outer ring into the female condom. If the penis enters to the side of the female condom or pushes one of the sides of the outer ring inside the vagina or anus, STOP, adjust the outer ring, and start again.

8. To take out the female condom, twist the outer ring and gently remove.

9. Tie a knot and dispose of it in the trash. Do not put it into the toilet.

Method 2: Use by insertive partner

1. Remove the inner ring. The ring can be placed on the OUTSIDE of the condom, as this can provide additional stimulation to the receptive partner.

2. Place the condom over the erect penis like a sock.

3. Add lubricant to the condom and/or to the partner's anus.

4. Holding both rings in place at the base of the penis, insert the penis into the anus or vagina.

As with the male condom, it is recommended to use the female condom only once, and to use a new one for each sex act. Advantages of female condoms are that they allow for more sensation by the 'top' (penetrating partner), and their material and texture mean that the 'bottom' (receiving partner) cannot feel the condom. Female condoms may be a more satisfactory option 
for men who do not enjoy using male condoms.

\section{Lubricants}

Lubricants (or 'lubes') are substances that reduce friction between the penis and the vagina or anus during sex. Lubrication helps prevent condom breakage, and decreases the risk of slippage during anal sex. For MSM especially, lubrication is very important during anal sex in order to prevent anal/rectal trauma.

There are two main types of lubricants: water-based and oil-based.

Water-based lubricants can be used with male latex condoms, as they do not damage the latex. Examples include Lubrica ${ }^{\circledR}, \mathrm{K}-Y$ Jelly ${ }^{\circledR}$ and Assegai ${ }^{\circledR}$. Most male and female condoms already have lubricants on them; however, adding lubricant is especially important for anal sex as the lining of the anus does not produce its own natural lubrication and is sensitive to tearing.

Oil-based lubricants must NOT be used with the male condom as they damage the latex and may increase the risk of condom breakage. Examples of oil-based lubricants include hand lotion, body lotion, baby oil, vegetable oil, cooking oil, massage oil and petroleum jelly (e.g. Vaseline®).

In many communities in Nigeria, water-based lubricants are not freely available and may be too expensive for most individuals to buy. In these cases, many individuals use other substances that provide lubrication during sex. It is critical when counselling clients about alternatives types of lubrication to emphasize that only water-based products be used. It is important to also educate a client that alternatives to lubrication that are oil-based, such as Vaseline, Baby oil, vegetable oil, are just as dangerous to use with a condom as oil-based lubricants.

\section{Giving advice on lubricant use to clients}

- Ask the client whether he usually uses a lubricant during sexual activity.

- If he does not use lubricants, ask whether he ever experiences pain or discomfort during sex.

- Explain what a lubricant is and inform him of the importance of ensuring smooth intercourse in order to minimize pain and the risk of tearing/bleeding.

- Explain that a lubricant can be used during intercourse regardless of whether a condom is used.

- Explain that condom use is the safest way to prevent HIV infection during sex, and that you recommend using a lubricant to ensure smooth intercourse as the anus does not produce natural lubrication or in situations where the woman's vagina does not produce enough lubrication and is dry.

- If possible, demonstrate correct lubricant use and give out water-based lubricants during the counselling session.

- Explain to clients that water-based lubricants (e.g. Lubrica and K-Y Jelly®) can be bought at most pharmacies.

As a counsellor it is important to be able to explain to clients what lubricants are and the difference between water-based and oil-based lubricants, and to recommend water-based lubricants with male condom use. 


\section{Condom use among MSM}

Despite high levels of awareness of HIV, condom use among MSM is not yet systematic or consistent. Many factors influence when and how an individual uses a condom. Decisions are often made based on individuals' perceptions of their partner, e.g. whether he or she looks healthy, whether he or she has had many partners, whether they have been together for a long time, and whether or not money is exchanged.

As relationships progress over time, condom use often declines as partners think that condoms are no longer needed, as they trust each other. Partners should emphasize the pleasurable aspect of condom use, in order to ensure long-term use in the context of stable partnerships.

Given the high number of sexual partners that some MSM often have, consistent and correct condom use is essential. Also given the difficulties of knowing the correct status of one's partner(s), the safest option is always to use a condom, with all types of partners, including onenight stands, clients who pay for sex, casual partners and long-term stable partners.

\section{Barriers to condom use}

There are many reasons why individuals may feel unable or unwilling to use condoms:

- They may believe condoms are not effective at preventing HIV and STIs

- They may have a negative attitude and misconceptions about condoms.

- They may believe that HIV cannot be transmitted during anal sex.

- They may find it difficult to insist on condom use with their partner because they are afraid that:

- Their partner might think they have been unfaithful

- Their partner or client might think they are HIV positive

- Their partner might think they do not trust them.

- They may lack knowledge and skills for correct condom use.

- They may think that sex is more pleasurable without condoms.

- MSW may earn less money or lose clients if they request sex with a condom.

- They may lack the power to suggest condom use, especially if they are in an imbalanced relationship, e.g. with differences in age and/or economic status.

- They may have impaired judgment due to the use of drugs or alcohol.

- They may be short on condom supplies, e.g. if engaging in several rounds of sex.

- They may not have easy access to condoms (e.g. if living in rural areas).

- They may be afraid to purchase condoms due to the societal stigma of either being viewed as having premarital sex or being unfaithful in marital relationships when admitting to condom use

- They may forget to carry condoms when going out.

Health care providers should be aware of the range of reasons why MSM clients do not use condoms. Health care providers should try to understand the main factors preventing their clients from using condoms on a case-by-case basis, and identify possible areas for offering support. 


\section{Negotiating condom use}

A useful approach to suggest condom use to one's partner(s) is to emphasize the positive role of condoms in enhancing pleasure and sexual wellbeing.

Highlighting the importance of condoms in terms of physical as well as emotional wellbeing may help promote condom use in short- and long-term partnerships.

\section{Condom negotiation tips include a range of options, which may include the following:}

- Use the clear stance of 'no condom - no sex'.

- Emphasize that condom use makes it easier to feel relaxed and enjoy the sexual act more.

- Bring a leaflet on condom use from the counselling session and use it to help introduce the topic to the partner.

- Make a packet of condoms easily available (e.g. on the bed, in a pocket, etc.).

- Make condom use an activity for both partners, and offer to put it on the partner using your hand.

- Make the experience sexy and exciting by using flavoured, coloured or ribbed condoms. Perceiving the condom as a 'sex toy' may help persuade the partner to use it.

- Suggest the use of a water-based lubricant (e.g. Lubrica and K-Y Jelly®) to increase sensitivity

- Offer to engage in a range of non-penetrative sexual activities (touching, mutual masturbation, rimming and oral sex) instead of penetrative sex.

- Suggest using the female condom instead of the male condom Female condoms can be a good way to flatter the partner by saying he has a big penis and needs to use the big condom.

\section{Summary}

- When used correctly and consistently, condoms are 80-95\% effective at preventing HIV transmission.

- Female condoms offer an added option in cases where male condoms cannot be used.

- Water-based lubricants, such as Lubrica ${ }^{\circledR}$ andK-Y Jelly® decrease the risk of slippage and breakage during anal intercourse.

- Condoms can be promoted as an added way of enhancing pleasure when negotiating condom use with a partner. 


\section{Practical exercise}

Penile models are needed in this exercise.

Working in pairs, one participant uses a penile model to demonstrate correct condom use to their partner, who should pay attention for any mistakes and test the demonstrator's knowledge by asking additional questions. Then they switch roles. Once both participants have given the demonstration, the facilitators share with the group those elements of the condom demonstration which were omitted, but which should have been included.

\section{Case studies}

Please read each of the following case studies and, drawing on the knowledge from this module, consider each discussion point. Feel free to draw on your personal experiences as well where appropriate. In each case study, describe what the counsellor/clinician could have done better, and how he or she could have incorporated some of the key information and messages from this module.

\section{Case Study 1}

During a counselling session, a MARP client tells the counsellor that he is tired of using condoms because they always seem to break. The counselor answers by saying that he is probably not using the condoms correctly, and that he should be more careful. He then hands over a few condoms to the client, and suggests that he keeps on trying.

\section{Discussion points}

- What could the counsellor have done better in answering the client's comment?

- What are the key components of correct condom use which the counsellor could have explained?

- $\quad$ Could the counsellor have done anything else in addition to giving out a few condoms?

- How would you have dealt with this situation?

\section{Case Study 2}

During a counselling session, a MARP client asks the counsellor about female condoms. The client says he has never seen one and was wondering what they looked like and how they were used. The counsellor tells him that the female condom is for women only and that he should therefore not worry about it.

Discussion points

- Is the counsellor right in stating that the female condom is for women only?

- In what situations could the female condom be useful to a client who has sex with men?

- What are the steps associated with correct female condom use?

- Is there more than one method for using the female condom for anal sex?

- How would you have dealt with this situation?

\section{Case Study 3}

During a counselling session, a MARP client explains that s/he would like to start using condoms with her/his long-term male partner, but does not see how s/he can persuade the partner to start using condoms; the partner would probably be angry and offended at the suggestion, and accuse him/her of lack of trust. The counsellor encourages the client to end the relationship, since continuing to have unprotected sex would put him at risk of HIV and STIs.

\section{Discussion points}

- $\quad$ Could the counsellor have helped the client by providing any other advice?

- What factors does he fail to take into account when he suggests that they end the relationship?

- Could the counsellor/clinician have used this as an opportunity to discuss the range of possible negotiation strategies for condom use?

- What strategies could the counsellor have suggested?

- Would couple's testing be a useful approach? What are the strengths and limitations of couple's testing in situations where partners may have more than one partner?

- How would you have dealt with this situation? 


\section{Module 8: Substance Abuse}

\section{Learning objectives}

By the end of this module, you should be able to:

- Understand why people abuse substances

- Understand how substances are taken

- Explain drug addiction and its effects

- List commonly abused substances and their effects

- Explain how substance abuse increases the risk of contracting HIV among MSM.

- How to help clients with drug addiction.

\section{Introduction}

Not all MSM use or abuse alcohol and drugs, but like most groups in society, there are members of the population that do. The precise level of substance use and abuse among MSM is difficult to determine. People generally abuse drugs and alcohol for many reasons such as:

- Escaping stress that they experience as a result of discrimination by society.

- Obtaining a sense of social acceptance and bonding.

- To escape or relax

- To relieve boredom

- To experiment

- To rebel

- To enhance body performance

\section{$\underline{\text { Knowledge section }}$}

Patterns of substance abuse include experimental, recreational and addiction (dependency). Routes of drug administration include orally, smoking, sniffing/snorting, eating, injecting/intravenous, and sub-cutaneous (skin-popping).Drug addiction is typically described as a transition from recreational use to compulsive drug taking and seeking.

\section{Exercise:}

How does drug addiction and abuse affect a person's life behaviorally, socially, physically, emotionally, financially?

As the period of abuse increases, emotional and behavioural problems are evident. You may recognize changes and effects on their lifestyle in the following areas:

- Behaviour - they are unreliable, deceptive and restless, and find it difficult to concentrate.

- Finances - they experience financial problems with cash flow and incur debt.

- Career - they change jobs or are unemployed frequently.

- Relationships - these are negatively impacted by instability and betrayal, and multiple 
partners and sex work may occur.

- Appearance - they show lack of self-care and personal hygiene, i.e. dirty clothing, unwashed hair.

- Emotions - they are irritable, depressed or aggressive

Table showing commonly abused drugs in Nigeria

\begin{tabular}{|c|c|c|c|c|c|c|}
\hline $\begin{array}{l}\text { CLASSIFICAT } \\
\text { ION }\end{array}$ & EXAMPLES & $\begin{array}{l}\text { STREET } \\
\text { NAMES(NIGERIA) }\end{array}$ & DESCRIPTION & SYMPTOMS & $\begin{array}{l}\text { DURATION } \\
\text { OF } \\
\text { EFFECTS(IN } \\
\text { HOURS) } \\
\end{array}$ & EFFECTS \\
\hline $\begin{array}{l}\text { NARCOTICS } \\
\text { (opiates) }\end{array}$ & $\begin{array}{l}\text { Opium, Heroin } \\
\text { Morphine } \\
\text { Codeine }\end{array}$ & Gbana,Smack, Horse & $\begin{array}{l}\text { White, grey or } \\
\text { brown, black, tar- } \\
\text { like substances, } \\
\text { smoked, sniffed, } \\
\text { injectable }\end{array}$ & $\begin{array}{l}\text { Euphoria, drowsiness, } \\
\text { respiratory depression, } \\
\text { apathy,reduced sexual } \\
\text { urge, nausea, } \\
\text { constricted pupils }\end{array}$ & 3-6 hours & $\begin{array}{l}\text { Watery eyes, } \\
\text { running nose, } \\
\text { irritability, } \\
\text { tremors, panic, } \\
\text { chills, cramps, } \\
\text { HIV, Hepatitis } \\
\text { B \& C } \\
\text { premature death }\end{array}$ \\
\hline STIMULANTS & $\begin{array}{l}\text { Cocaine } \\
\text { Amphetamine } \\
\text { Crack, Cocaine }\end{array}$ & $\begin{array}{l}\text { Coke, Coco, Cocktail, } \\
\text { Crack, Chunk, Rock, } \\
\text { blow etc }\end{array}$ & $\begin{array}{l}\text { Fluffy, white, } \\
\text { crystalline powder } \\
\text { tablet or capsule, } \\
\text { smoked, sniffed }\end{array}$ & \begin{tabular}{lr} 
Increased & \multicolumn{2}{c}{ alertness, } \\
excitation & \multicolumn{2}{c}{ euphoria, } \\
increased pulse rate, \\
insomnia, loss of \\
appetite
\end{tabular} & $\begin{array}{l}\text { Cocaine 1-2hrs, } \\
\text { Amphetamine 2- } \\
\text { 4hrs }\end{array}$ & $\begin{array}{l}\text { Disorientation, } \\
\text { apathy, } \\
\text { irritability, } \\
\text { depression, } \\
\text { Hepatitis B \& C, } \\
\text { HIV. }\end{array}$ \\
\hline $\begin{array}{l}\text { DEPRESSANT } \\
\mathrm{S} \quad \text { (sedative } \\
\text { hypnotics) }\end{array}$ & $\begin{array}{l}\text { Barbiturates } \\
\text { Benzodiazepine- } \\
\text { pines, valium, } \\
\text { Alcohol(beer, } \\
\text { wine, gin etc) }\end{array}$ & $\begin{array}{l}\text { Sleeping pills/tablets, } \\
\text { Booze, Ogogoro, Emu, } \\
\text { Giya, Nimanya }\end{array}$ & $\begin{array}{l}\text { Tablets or capsules } \\
\text { taken orally or } \\
\text { injected. Liquid } \\
\text { taken orally. } \\
\text { Capsule, tablet }\end{array}$ & $\begin{array}{l}\text { Disorientation, } \\
\text { memory impairment, } \\
\text { slurred speech, motor } \\
\text { in coordination }\end{array}$ & $\begin{array}{l}\text { Barbiturates (1- } \\
\text { 16hours) } \\
\text { Others(4- } \\
\text { 8hours) } \\
\text { possible death }\end{array}$ & $\begin{array}{l}\text { Anxiety, } \\
\text { insomnia, } \\
\text { tumors, } \\
\text { delirium, } \\
\text { convulsion, liver } \\
\text { cirrhosis } \\
\text { (alcohol), HIV, } \\
\text { Hepatitis B \& C. }\end{array}$ \\
\hline $\begin{array}{l}\text { HALLUGINOG } \\
\text { ENS }\end{array}$ & $\begin{array}{l}\text { LSD(Lysergic } \\
\text { acid } \\
\text { Diethylamide), } \\
\text { PCP(phencyclidi } \\
\text { ne }\end{array}$ & $\begin{array}{lr}\text { PCP } & \text { elephant, } \\
\text { tranquilizer. } & \text { Not } \\
\text { common on Nigerian } \\
\text { streets }\end{array}$ & $\begin{array}{l}\text { Powder, liquid } \\
\text { taken orally or } \\
\text { injected. } \\
\text { Green(Fresh) }\end{array}$ & $\begin{array}{l}\text { Thinking disorder, } \\
\text { illusion and } \\
\text { hallucinations, poor } \\
\text { perception of time and } \\
\text { distance }\end{array}$ & $8-12$ hours & $\begin{array}{l}\text { Flashbacks, } \\
\text { panic evidence, } \\
\text { psychosis, bad } \\
\text { trips }\end{array}$ \\
\hline CANNABIS & $\begin{array}{l}\text { Marijuana } \\
\text { Hashishi }\end{array}$ & $\begin{array}{l}\text { Igbo, stone, salad, Indian } \\
\text { hemp, Ganja, kaya, } \\
\text { Goofo, pot etc }\end{array}$ & Brownish (dry) & $\begin{array}{l}\text { Euphoria, distorted } \\
\text { perception, impaired } \\
\text { concentration, relaxed } \\
\text { inhibitations }\end{array}$ & 2-4 hours & $\begin{array}{l}\text { Insomnia, } \\
\text { hyperactivity, } \\
\text { lung disease, } \\
\text { brain damage. } \\
\text { Affects sexual } \\
\text { behavior }\end{array}$ \\
\hline INHALANTS & $\begin{array}{l}\text { Aerosols, } \\
\text { gasoline }\end{array}$ & $\begin{array}{l}\text { Glues, solvents, } \\
\text { butylnitrate } \\
\text { (room odorizers) }\end{array}$ & & $\begin{array}{l}\text { Liquid form, gas form } \\
\text { usually inhaled or } \\
\text { sniffed }\end{array}$ & & $\begin{array}{l}\text { Vision } \\
\text { disturbance, } \\
\text { impaired } \\
\text { judgement, } \\
\text { reduced muscle } \\
\text { andr reflex } \\
\begin{array}{l}\text { control, heart } \\
\text { failure, sudden } \\
\text { death }\end{array} \\
\end{array}$ \\
\hline
\end{tabular}

How does substance abuse increase HIV vulnerability?

Abusing drugs and alcohol can make individuals more vulnerable to contracting HIV because it may cause them to engage in riskier sexual behaviour including: 
- not using condoms

- having sex with a stranger

- having an increased number of sexual partners

- engaging in prolonged sex sessions

- Having unsafe sex to acquire drugs.

People who inject drugs, either into their veins or into their muscles, may be directly at risk for acquiring HIV through sharing drug equipment such as needles and syringes

Sexual partners of HIV-infected intravenous drug users (IDUs) may be at risk of contracting HIV through sexual transmission.

\section{How do I help my clients who are abusing substances?}

- The best thing to do is to refer them for professional specialized help.

- Find out where the best place to refer them is in your area.

\section{Exercise}

\section{Case Study}

Shehu comes to you for pre-HIV-test counselling. He looks very nervous and distracted, has dark rings under his eyes, and gives off the odour of being unwashed. While you are trying to counsel him, he is restless and keeps scratching his body. Shehu speaks very quickly, telling you that he sometimes sells sex to make ends meet, and does not remember if he uses condoms with clients because he just wants to get the money to buy drugs.

What do you think is the cause of Shehu's behaviour?

What support do you think Shehu needs?

\section{Summary}

- Stigma and rejection from others may cause MSM to abuse substances and have a drug addiction.

- Substance abuse is common among MSM and may lead to increased risk-taking behaviour.

- HIV and other STIs such as Hep B can be contracted from injecting drug use.

- A trained health care professional should manage substance abuse cases. 


\section{Module 9: Risk Reduction Counseling with MARP clients}

\section{Learning objectives}

At the end of this module, you should be able to:

- Explain how risk-reduction counseling(RRC) can be adapted for MSM clients

- Describe key areas that should be addressed in a risk-reduction counseling session with MSM clients.

- Describe how inappropriate language, personal bias and stigma can be overcome when counselling MSM.

- List different ways to improve health care services for MSM.

- Describe different ways for engaging MSM in sexual-health services.

\section{Introduction}

This module will explore methods to better adapt behavioural interventions such as riskreduction counseling and HIV testing services to meet the needs of clients identified as MSM. It will explore how personal bias, language and misinformation can negatively affect the health and wellbeing of MSM clients, as well as how these barriers can be overcome. You will learn tips and strategies that could improve your ability to effectively counsel MSM in addition to various ways of reaching out to MSM within your community.

\section{$\underline{\text { Knowledge section }}$}

Risk-reduction counseling is a behavioural intervention that attempts to decrease an individual's chances of acquiring HIV and other STIs. This is achieved by helping people identify and change specific behaviours that may put them at risk of becoming infected and reinforcing healthy behaviours that can keep them healthy. Globally, it has been recommended that risk-reduction counseling be included in standard HIV testing procedures, particularly for individuals with high-risk behaviours. Risk-reduction counselling has been shown to be effective in increasing condom usage and in decreasing the risk of future STIs. As a prevention tool, risk-reduction counseling is the most effective when it is patient-centred, meaning that the counselling session focuses on the specific risks, needs and thoughts of the client. Engaging any individual about his or her sexual practices is not easy particularly when working with MSM clients. This process can be made more difficult by social stigma, discrimination and misinformation about the common sexual practices of this target population. 


\section{Risk-reduction Counseling Steps}

\section{Step 1: Assess the risk behaviour of clients}

In order to assist clients in developing risk-reduction goals, it is important to gain a better understanding of their sexual practices, including both safe and risky behaviours. Focus can be placed on behaviour over the previous three months, as this may affect their need for further HIV testing.

This basic assessment can be achieved by asking them key questions regarding

- The number and type of sexual partners they have,

- The types of sexual acts they have engaged in,

- In addition, their use of alcohol or other substances.

\section{Step 2: Assist clients in identifying risk behaviour to address}

Clients should select a behaviour that they are motivated to change. This can be one that is causes some type of physical or emotional distress. It is important that clients be significantly involved in choosing which behaviour to address. When they are actively involved in the identification process, they will be more motivated to follow through on the risk-reduction goals or strategies than if the counsellor selects the behaviour.

\section{Step 3: Discuss the 'cost and benefits' of this behaviour}

Once a behaviour has been selected it will be helpful to assist clients in exploring and understanding the reasons why they engage in this behaviour. This will involve discussing their motivators or 'benefits' for doing so. Additionally, it is critical also to explore and discuss the consequences of this behavior. For example, when discussing the 'cost and benefits' of engaging in unprotected vaginal or anal sex, a participant may list 'benefits' such as, 'it feels good', 'it is more intimate' or 'it is cheaper than buying condoms', while some 'costs' might be the danger of becoming infected with an STI or HIV, or the fear and emotional stress associated with not knowing their HIV status. The counsellor should use the 'cost and benefits' listed by their clients to assist them in understanding why they engage in the risk behaviour and why they should consider altering that behaviour.

\section{Step 4: Set goals}

Once clients have a deeper understanding of why they engage in the risk behaviour and motivators that influence them, they should create a personalised goal to change this behaviour in some way to become safer.

This goal should be specific, achievable and measurable. Goals that are less detailed can be difficult to achieve. Most importantly, a behaviour-change goal should be realistic for clients and based on their specific circumstances. Setting a behaviour-change goal that is impossible for them to achieve right away may lead them to becoming de-motivated or disappointed in themselves. For example, it may be unrealistic for a client who very regularly has a large number of sexual partners to set a behaviour-change goal of becoming monogamous. Instead, a smaller but achievable goal might be for such clients to reduce their sexual partners to a smaller number of people, which may also be something that they can sustain over time.

\section{Step 5: Discuss barriers}

It can also be helpful to discuss with clients any potential barriers that may prevent them from 
achieving their goal and to help them to develop strategies to overcome them. Barriers could include things like pressure from friends or an addiction to a drug. Predicting potential barriers that could make behaviour change difficult for the client is particularly helpful if you have infrequent contact with clients or will only see them once.

\section{Step 6: Reinforcement}

Ultimately, changing behaviour can be a difficult process, therefore it can be helpful to make clients feel proud and motivated when they conclude their session, and to remind them that with a new goal comes a new opportunity to improve their behaviour. Furthermore, it needs to be emphasized that not all clients engage in risky behaviour. Clients may easily be engaging in a number of safe behaviours that they enjoy, and reinforcing these behaviours is a great way to encourage their self-esteem and support behaviours that are protecting their health.

\section{Is risk-reduction counseling done differently with MSM?}

Risk-reduction counselling can be conducted with MSM just like any other client as long as it takes into account their specific needs, background and challenges. Therefore, each riskreduction session, no matter the background of the client, will be unique and require different strategies and techniques. While there is no standardized risk-reduction model specifically for MSM, there are a number of factors that can influence a counselling session with MSM which need to be taken into consideration.

\section{Understanding the effect of personal beliefs and knowledge}

The most significant influence in a counselling session is the counsellors themselves, and the knowledge, opinions and beliefs they bring with them. Unfortunately, many counsellors share the beliefs of some communities and cultures that have misconceptions or negative perceptions about MSM. Counsellors with negative perceptions of MSM must take measures to ensure that their personal beliefs are not affecting the service the client is receiving. When health care providers let their own values and beliefs affect the services they provide, they can easily be hindering the assistance of those individuals who need their help the most. Some counsellors may not approve of a man having anal sex with another man but they have a responsibility and a duty to help their clients protect themselves and to engage in safe sexual behaviours, whatever those behaviours may be.

\section{Dealing with clients who do not want to disclose their sexual preference (closeted clients)}

Some MSM may not feel comfortable enough to disclose their personal sexual practices to a health care provider. One explanation for this may be because of the social stigma and discrimination they face in their communities. As a counsellor, this can be a significant challenge to successfully helping a client. After all, if clients are unwilling to explain their true sexual practices, how can effective risk-reduction counselling take place? One possible solution is to treat each and every client equally. If clients feel too uncomfortable to disclose their sexual orientation, a counsellor may ask the wrong questions For example, if counsellors only ask questions about having sex with women, clients may not openly disclose that they are also having sex with men. To prevent these possible oversights, a counsellor can standardize the 
questions they use and keep them the same for each client. For example, when asking clients about their number of sexual partners, counsellors could ask them, even those who openly identify as MSM, how many men and women they have engaged with sexually.

\section{Significance of confidentiality}

All risk-reduction counselling sessions, regardless of the client, must remain completely private between the client and the counsellor. For MSM in particular, ensuring confidentiality is critical. MSM, particularly those who have not come out, could face a number of negative effects should knowledge of their sexual behaviour be made public. If a MSM client begins the session with this fear or concern, they may be less likely to engage productively in the counselling; therefore, it must be a priority in each session to express to the clients the ways in which their privacy will be respected.

\section{What sexual behaviour should be addressed in a risk-reduction session with a MARP client?}

In many risk-reduction sessions, sexual behaviour is generally discussed with the client based on the types of sexual activities they are engaging in. The types of behaviours discussed will therefore be unique for each and every person, including MSM. Keep in mind that not all MSM, like everyone else, engage in every sexual act. For example, some may choose not to engage in any type of anal sex. Therefore, when discussing sexual behaviour with MSM clients during a risk-reduction session, it is important to focus on the behaviours specific to each individual client.

It is important for a counsellor to be familiar with various sexual activities and their risks, and possible alternatives to those activities, in order to provide the best options for behaviour change to a client. For more information on anal sex and common sexual practices of MSM, please refer to module 4. Below is a brief review of some risk behaviours, influences on behaviour and possible behaviour changes for MSM clients that may be discussed during a risk-reduction session. 


\section{Exercise}

- List some risky sexual behaviours.

- List some influence on sexual behaviour.

- Possible behaviour changes for MSM that may be discussed during a risk-reduction session.

\section{Table of risky sexual behavior}

\begin{tabular}{|c|c|c|c|}
\hline Sexual practice & $\begin{array}{l}\text { Between man \& woman }(M, \\
W)\end{array}$ & Between man \& man $(M, M)$ & $\begin{array}{l}\text { HIV/STI risk level (low, } \\
\text { medium, high) }\end{array}$ \\
\hline Kissing & $M-W$ & $M-M$ & Low risk \\
\hline Hugging & $M-W$ & $M-M$ & Low risk \\
\hline Mutual masturbation & $M-W$ & $M-M$ & Low risk \\
\hline Oral sex & $W-M, M-W$ & $M-M$ & Medium risk \\
\hline Anal stimulation & $M-W, W-M$ & $M-M$ & Medium risk \\
\hline $\begin{array}{ll}\text { Unprotected } & \text { sexual } \\
\text { intercourse } & \\
\end{array}$ & $M-W$ & - & High risk \\
\hline Unprotected anal intercourse & $M-W$ & $M-M$ & High risk \\
\hline $\begin{array}{l}\text { Unprotected sexual } \\
\text { intercourse with a group }\end{array}$ & $M-W$ & $M-M$ & High risk \\
\hline
\end{tabular}




\section{Exercise}

Below are a series of case studies, each of which describes a MSM client. For each example, use the six steps of risk-reduction counselling provided.

If you have a study partner, role play each case study in a counselling session, with one person acting as the client and the other as the counsellor

\section{Case Study}

Effiong is a 31-year-old man who is married to a woman and has three children. On Saturday nights, he likes to go to a local bar across town that is known for being frequented by gay men. On these nights, he often drinks heavily at the bar and waits to be approached by one of the men. Frequently, he will offer to drive one of them home in exchange for penetrative anal sex. He says he does not like to use condoms because they do not fit well and he does not carry them because he does not want his wife to suspect him.

\section{Improving communication during RRC}

Using the appropriate language and terminology with MSM clients is a key component to creating an environment in which they feel comfortable engaging with a counsellor and discussing their sexual behaviour. The following are a few useful tips that help guide the use of language during a session with MSM.

Use the types of words the client is using: A counselor who is comfortable using the same language and slangs as a client uses to describe his sexual practices can create a sense of understanding. For example, the terms passive and bottom both refer to acting as the receptive partner during anal sex but a client may use the terminology that is applicable for his social network or community.

Do not automatically label clients or assume details about their behavior: Culturally, it may be common to assume things about some MARPs such as MSM because of the way they dress or act. For example, you might assume that an effeminate client who dresses in women's clothing acts only as the receptive partner during anal sex, but in fact outward appearance cannot be linked to sexual practices. Making these types of assumptions could not only offend clients but also influence the type of questions that are asked and the types of responses they are able to provide.

Do not include value judgements or personal beliefs: It is not the role of counselors to judge clients because this will not provide clients with any helpful service. For example, if a man is married to a woman but having sex with other men, or is abusing drugs, or is a sex worker, a counselor should not encourage him to stop having sex with men or engaging in other high risk behaviours because he is 'cheating on his wife' or behaving immorally. Instead, the counselor could encourage the man to remain faithful to his wife because decreasing his number of partners could protect him from HIV or in the case of a sex worker using condoms for every sexual act with clients will protect him or her against HIV. 
Repeat statements about behaviour or identity in order to clarify their meaning: There are many ways people identify themselves, their sexual orientation and their sexual behaviours. Given the many definitions and possible behavioural implications of each, it can be beneficial, when clients label themselves in a specific way, for the counselor to ask them for a deeper explanation of what that label means. This will allow the counselor to fully understand the behaviours and practices of clients.

Create a safe space: This can be achieved by making your clients feel comfortable by reminding them of their ensured confidentiality and asking questions to show you are open minded, knowledgeable and non-judgemental. Making informal but affirming references to a MSM community that your clients can identify with, can be a passive method of informing them that you are someone who is non-judgmental of their community.

\section{Exercise}

\section{Risk-reduction counseling practice (Share RRC Steps outline)}

The following case studies below show some sexual practices of MARPs, for each case study address the following questions:

- What are the key risk behaviours of the client?

- What strategies would you create to help each client reduce his risk?

- How would you prevent the client from feeling judged?

- What types of language would you use when speaking with the client?

If possible, identify a partner to practice these case studies with. One individual should be the client and the other the health care worker.

\section{Case Study}

Osas is 42 years old and has been married to a woman for many years. He has come to your clinic for an HIV test and during the counselling session tells you that his wife wants to have a baby so when they have sex, they do not use condoms. Osas also likes to have sex with other men sometimes. He is afraid of his wife finding out and so does not go to the bars that gay men frequent. Instead, he often will find a male sex worker and pay him to have sex in private. Osas says he only has sex with a man about once a month and that because he does not like the way condoms feel he does not use them.

\section{How can I engage with MSM communities for HIV Testing and RRC?}

Because of discrimination and stigma within their communities, MSM may be forced to lead secret lives and not have their sexual behaviour openly known. This can make both individual MSM difficult to find and entire MSM communities hard to reach. Given the history of lack of service provision, it can be problematic to help MSM access vital services like HIV testing.

Additionally, many service providers work within communities where they themselves would face stigma, discrimination or violence for advertising any MARP-friendly services they may 
offer. Therefore, individualized methods need to be developed that not only reach MSM communities but also protect service providers. The following are a few useful strategies to use.

\section{Identifying and engaging a key informant}

Often MSM operate within close social networks, depending on the level of discrimination or stigma in the community where they are based, these networks can either be closed and highly private, or more open and easily accessible. Identifying and building a relationship with a key member of a MSM community such as an MSM's social network can be highly valuable. This key informant can give insight into the behaviours of MSM in their network, such as where and how they socialize. They can also act as a promoter for your services within their social networks.

\section{Creating a trusting relationship}

Establishing a trusting mutual relationship with MSM in the community is critical for creating a sustained relationship. This process can begin with a key informant who may then be able to spread this information to other members of the community. Whether on behalf of an organization or individually, being upfront and clear in your intentions are necessary in establishing strong community ties.

\section{Educating the community}

Once a trusting relationship has been established with a MSM community, attempts can then be made to educate them about the services or activities that are available for their participation. This would also be an excellent opportunity to address any concerns they may have about confidentiality by explaining the ways in which this is guaranteed by your service or organization. Promoting MARP-friendly services using other MSM clients as face-to-face promoters can effectively spread information about your services while protecting them from public criticism.

\section{Exercise}

Individually, in groups or in pairs, brainstorm different ways you could engage MSM in your community on an individual, organizational and community level. Think of reasons why it might be difficult to contact or interact with MARPs in your community and how you might overcome those challenges. Share these ideas with your group or co-workers.

\section{Summary}

- Risk-reduction counseling is an effective behavioural intervention that can help reduce an individual's risk for STIs and HIV.

- Appropriate and socially relevant language should be used with MSM to make them feel comfortable. 
- Personal bias or stigma should be addressed before working with a MSM client so as not to affect the client negatively.

- The use of health care services by MSM communities can be improved by:

1. Identifying and engaging key informants

2. Creating trusting relationships

3. Educating the community 


\section{APPENDIX}

\section{Sample Pre-test and Post-Test Questions}

Thank you for your interest in this MARPs sensitization training programme for MSM. Please complete the questionnaire before starting the programme.

1. MARPs mean?

2. 3 examples of MARPs groups are

3. High rates of unprotected sexual partnerships is one of the main routes for MSM to transmit or contract HIV (Agree or Disagree)

4. Discrimination is a form of behavior that results in unequal or unfair treatment. (Agree or Disagree)

5. HCP code of conduct in Nigeria requires that all patients be treated without exemption (Agree or Disagree)

6. Moral judgment is a form of internal stigma. (Agree or Disagree)

7. Social withdrawal is a form of external stigma. (Agree or Disagree)

8. Stereotyping may lead to stigmatizing behavior (Agree or Disagree)

9. Kissing is a form of sexual behavior. (Agree or Disagree)

10. People attracted to members of the opposite sex are called

11. People attracted to members of the same sex are called

12. People who are attracted to both men and women are called.

13. LGBTI means.

14. Stigma and discrimination makes sexual minorities vulnerable to HIV. (Agree or Disagree)

15. Mutual masturbation has a low risk of HIV infection. (Agree or Disagree)

16. Only homosexual men practice anal sex. (Agree or Disagree)

17. A 'receptive' partner is

18. An 'insertive' partner is

19. The risk of HIV infection during unprotected receptive anal sex is higher than unprotected vaginal sex (Agree or Disagree) 
20. Most risk-reduction sessions following HIV testing assume sexual intercourse to be penile-vaginal. (Agree or Disagree)

21. When a man reports anal sex with a man during counselling you should ask if he takes the insertive or receptive role. (Agree or Disagree)

22. Genital warts are caused by (a) HIV (b) HPV (c) Chlamydia (d) Syphilis

23. A common symptom of an STI is

24. Condoms are 80-95\% effective at preventing HIV and STIs. (Agree or Disagree)

25. If a MSM client complains that condoms always seem to break when he uses them, which would be the best response for a counsellor to give?

a. Tell the client to use commercial condoms instead of the free ones.

b. Provide a condom demonstration to the client, and then ask him to repeat it.

c. Hand a few condoms to the client to replace the broken ones.

d. Suggest he adds a water-based lubricant to reduce friction.

26. When putting on a male condom, it is necessary to ensure that there is air at the tip to allow room for semen. (Agree or Disagree)

27. A common condom use error is....

28. Lubricants can be oil-based or water-based. (Agree or Disagree)

29. is an example of a water-based lubricant.

30. People abuse drugs because of?

31. Cocaine can stimulate high sexual urge (Agree or Disagree)

32. People who inject drugs are at risk of acquiring HIV through sharing drug equipment such as needles with an infected person. (Agree or Disagree)

33. Asking key questions about a MSM client's sexual behaviour will
a. cause the client to feel bad about himself
b. provide an assessment of the client's sexual risk taking
c. make the counsellor appear judgmental
d. reinforce the client's behavior

34. Defining specific, achievable and measurable take into consideration the influences and motivations of the client can help with risk reduction.
a. risks
b. costs
c. counselling
d. goals

35. When counselling a MSM client, the HCP's opinions and judgments should not affect his/her behaviour towards the client. (Agree or Disagree) 


\section{Pre-Post Test Answers}

1. MARPs mean? Most At Risk Populations

2. Examples of MARPs include: FSW, MSM, IDU, Prisoners/Incarcerated populations

3. High rates of unprotected sexual partnerships is one of the main route for MARPs to transmit or contract HIV (Agree )

4. Discrimination is a form of behavior that results in unequal or unfair treatment. (Agree )

5. HCW code of conduct in Nigeria requires that all patients be treated without exemption (Agree )

6. Moral judgment is a form of internal stigma. (Disagree)

7. Social withdrawal is a form of external stigma. (Disagree)

8. Stereotyping may lead to stigmatizing behavior (Agree )

9. Kissing is a form of sexual behavior. (Agree)

10. People attracted to members of the opposite sex are called: Heterosexuals

11. People attracted to members of the same sex are called: Homosexuals

12. People who are attracted to both men and women are called: Bisexuals

\section{LGBTI means: Lesbian, Gay, Bisexual, Transgendered, Intersex}

14. Stigma and discrimination makes sexual minorities vulnerable to HIV. (Agree)

15. Mutual masturbation has a low risk of HIV infection. (Agree)

16. Only homosexual men practice anal sex. (Disagree)

17. A 'receptive' partner is one that is penetrated in the anus by aman's penis

18. An 'insertive' partner is one that penetrates another person's anus with his penis

19. The risk of HIV infection during unprotected receptive anal sex is higher than unprotected vaginal sex (Agree)

20. Most risk-reduction sessions following HIV testing assume sexual intercourse to be penile-vaginal. (Agree)

21. When a man reports anal sex with a man during counselling you should ask if he takes the insertive or receptive role. (Agree)

22. Genital warts are caused by (b) HPV 
23. A common symptom of an STI is: Painful urination, sores, discharge, swollen testicles

24. Condoms are 80-95\% effective at preventing HIV and STIs. (Agree )

25. If a MARP client complains that condoms always seem to break when she uses them, which would be the best response for a counsellor to give?

(b) Provide a condom demonstration to the client, and then ask him to repeat it.

26. When putting on a male condom, it is necessary to ensure that there is air at the tip to allow room for semen. (Agree )

27. A common condom use error is: rubbing off all the lubrication with the palm of the hand

28. Lubricants can be oil-based or water-based. (Agree)

29. Lubrica, KY Jelly, Assegai is an example of a water-based lubricant.

30. People abuse drugs to: Relax, Fit-in, Relieve stress

31. Cocaine can stimulate high sexual urge (Agree)

32. People who inject drugs are at risk of acquiring HIV through sharing drug equipment such as needles with an infected person. (Agree)

33. Asking key questions about an MARP client's sexual behaviour will.

(b) provide an assessment of the client's sexual risk taking

34. Defining specific, achievable and measurable ................ that take into consideration the influences and motivations of the client can help with risk reduction.

(d) goals

35. When counselling an at-risk MARP client, the HCW's opinions and judgments should not affect his/her behaviour towards the client. (Agree) 


\section{Bingo Sheet}

\begin{tabular}{|l|l|l|}
\hline $\begin{array}{l}\text { Someone who speaks more } \\
\text { than two languages }\end{array}$ & $\begin{array}{l}\text { Someone who loves to drink } \\
\text { beer }\end{array}$ & $\begin{array}{l}\text { Someone who distributes } \\
\text { condoms. }\end{array}$ \\
\hline $\begin{array}{l}\text { Someone who has been to a } \\
\text { drug den/bunk }\end{array}$ & $\begin{array}{l}\text { Someone who has had an STI } \\
\text { before }\end{array}$ & $\begin{array}{l}\text { Someone who has more than } \\
\text { three children }\end{array}$ \\
\hline $\begin{array}{l}\text { Someone who has visited a } \\
\text { brothel before }\end{array}$ & $\begin{array}{l}\text { Someone who has been called } \\
\text { names such as, Ashawo, } \\
\text { Homo or Drug Addict }\end{array}$ & $\begin{array}{l}\text { Someone who has used a } \\
\text { lubricant before }\end{array}$ \\
\hline $\begin{array}{l}\text { Someone who enjoys or has } \\
\text { had anal sex before }\end{array}$ & $\begin{array}{l}\text { Someone who has been tested } \\
\text { for HIV in the last 3 months. }\end{array}$ & $\begin{array}{l}\text { Someone who has a friend } \\
\text { who is gay or lesbian. }\end{array}$ \\
\hline
\end{tabular}




\section{Post-training Commitment}

I have completed the providing MARP-friendly services training for healthcare workers. We covered topics about MARPs in Nigeria and role and responsibilities of healthcare workers to MSM communities, stigma and its effects, sexual orientation, common sexual practices among MSM, HIV \& STIs, condoms and lubricant use and substance mis-use.

Focus was placed on how to explore sexual practices among MSM clients and how to approach risk reduction counselling.

I am committed to using this new knowledge and these new skills in my daily work.

I am also committed to being more aware of MSM and the issues affecting their sexual health.

The current code of conduct for health workers in Nigeria, states that every patient has the right to "confidentiality" about their medical issues and anything they share with a medical practitioner unless they are causing harm to another human being or someone is causing harm to them, "privacy," during any medical exams or tests and "equal treatment" without judgment for their behavior or identity.

- I/we will give everyone the same type of medical care, to the highest quality possible at our facility, regardless of their sexual orientation or behaviour.

- I/we welcome everyone including sexual minorities and their families into my/our practice and offer all health services to patients on an equal basis, regardless of sexual orientation, gender identity, sexual behavior, marital status, and other non-medically relevant factors

- I/we respect the visitation and healthcare decision-making rights of MSM patients/clients, their unmarried partners, their non-biological children, and any others they may define as family for the purposes of visitation and healthcare decision-making.

- I/we commit to taking steps to make my practice fully inclusive to MSM clients as reflected in written forms, policies and procedures, appropriate training for all clinical and administrative staff, and standardized assessments.

- I/we commit to taking steps to learn about the unique health concerns of MSM clients and families so that I/we can provide the highest quality care to all people.

- I/we will maintain confidentiality about an individual's orientation and/or behavior just as we would keep medical records of any client completely confidential

Signed

Date 


\section{POST-TRAINING FOLLOW-UP}

In order to assess the effectiveness of this course we would like to contact health care workers three months after the training completion.

May we contact you to complete a short questionnaire after completion of the course? (Please circle one)

Yes No

Please provide your work contact details:

Name and surname

Facility name \& address

Email address

Contact number

Alternate contact number. 


\section{DAILY TRAINING EVALUATION FORM}

DAY

This questionnaire seeks to evaluate the daily training sessions.

Please answer all the questions and feel free to make additional comments at the end of the questionnaire.

1. How would you rate today's session?

$\square$ Poor $\square$ Fair $\square$ Jood $\square$ Jery Good $\square$ xcellent

2. Which specific topics appealed to you the most?.....

3. What did you like the least about today's session?

4. What topic/issues will you like us to deal with better in future trainings?

5. What would you like the facilitator to do better?

6. Other additional comments 


\section{MARPs Sensitivity Training for Healthcare Workers}

Date:

Venues:

Participants: Doctors, Counsellors, and other healthcare providers

Goal of the training is to equip healthcare workers with the necessary skills and knowledge to provide services that support and adequately cater for Most At Risk Populations (MARPs) and their unique needs within the Nigerian Healthcare setting.

\begin{tabular}{|c|c|}
\hline TIME & DAYS AND SESSIONS \\
\hline & DAY 1: \\
\hline $8.00-8.30$ & $\begin{array}{ll}\text { - } & \text { Registration } \\
- & \text { Welcome address } \\
\text { - } & \text { Introductions } \\
\text { - } & \text { Housekeeping/forming committees/ground rules } \\
\end{array}$ \\
\hline $8.30-9.00$ & $\begin{array}{ll} & \text { Pre-test } \\
\text { - } & \text { Participants training expectations } \\
\text { - } & \text { Training objectives } \\
\end{array}$ \\
\hline $9.00-10.30$ & Most At Risk Populations (MARPs) and HIV in Nigeria \\
\hline $10.30-11.00$ & TEA-BREAK \\
\hline $11.00-12.30$ & Role and responsibilities of healthcare workers to MSM communities in Nigeria. \\
\hline $12.30-1.30$ & Stigma and its effects (1) \\
\hline $1.30-2.30$ & LUNCH BREAK \\
\hline $2.30-3.30$ & Stigma and its effects (2) \\
\hline $3.30-4.30$ & Sexual orientation (1) \\
\hline $4.30-5.00$ & Sexual orientation (2) \\
\hline $5.30-6.00$ & Daily evaluation \\
\hline & DAY 2: \\
\hline $8.30-9.00$ & Plenary \\
\hline $9.00-10.30$ & Common sexual practices among MSM \\
\hline $10.30-11.00$ & TEA-BREAK \\
\hline $11.00-12.30$ & HIV and sexually transmitted infections (STIs) (1) \\
\hline $12.30-1.30$ & LUNCH BREAK \\
\hline $1.30-2.30$ & HIV and sexually transmitted infections (STIs) (2) \\
\hline $2.30-3.30$ & Condom and lubricant use (1) \\
\hline $3.30-4.30$ & Condom and lubricant use (2) \\
\hline $4.30-5.00$ & Daily evaluation \\
\hline & DAY 3: \\
\hline $8.30-9.00$ & Plenary \\
\hline $9.00-10.30$ & Substance misuse (1) \\
\hline $10.30-11.00$ & TEA-BREAK \\
\hline $11.00-12.30$ & Substance misuse (2) \\
\hline $12.30-1.30$ & Risk reduction counseling with MSM (1) \\
\hline $1.30-2.30$ & LUNCH BREAK \\
\hline $2.30-4.00$ & Risk reduction counseling with MSM (2) \\
\hline $4.00-4.30$ & $\begin{array}{ll}\text { - } & \text { Daily evaluation } \\
\text { - } & \text { Post-test } \\
\text { - } & \text { Post-course assessment } \\
\end{array}$ \\
\hline $4.30-5.00$ & $\begin{array}{l}\text { - Post training commitment, } \\
\text { - } \quad \text { Closing }\end{array}$ \\
\hline & DEPARTURE \\
\hline
\end{tabular}




\section{References:}

FMOH HIV/STI Integrated Biological and Behavioral Surveillance Survey 2007

FMOH HIV/STI Integrated Biological and Behavioral Surveillance Survey 2010

NACA The National HIV/AIDS Behaviour Change Communication Strategy 2009 - 2014

Most-At-Risk Populations for HIV and AIDS in Nigeria. Desk Review Commissioned by ENHANSE June 2007

Desmond Tutu HIV Foundation (2011) Men who have Sex with Men: An Introductory Guide for Health Care Workers in Africa Revised edition 2011

Anova Health Institute (2010) From top to bottom: a sex-positive approach for men who have sex with men - a manual for healthcare providers.

Reducing Stigma and Discrimination Related to HIV and AIDS: Training for Health Care Workers Engender Health (2004)

Smith, D., Grohskopf, L., Black, R. \& Al, E. (2005). Antiretroviral post-exposure prophylaxis after sexual, injection-drug use, or other non-occupational exposure to HIV in the United States: Recommendations from the US Department of Health and Human Services. MMWR Recomm Rep., 1-20.

http://www.medscape.com/viewarticle/755687_4

IAS 2010, Vienna Austria Abstract: Male sex work in Nigeria: a population-based estimate of a hidden and vulnerable population- A. Karlyn ${ }^{1}$, S. Adebajo ${ }^{2}$, E. Nwachukwo ${ }^{2}$, J. Tocco ${ }^{3}$, L. Abiodun ${ }^{4}$, O. Anene ${ }^{5}$, D. Ojiyoma ${ }^{6}$, S. Sangowawa ${ }^{4}$, S.Kellerman ${ }^{7,8}$

${ }^{1}$ Population Council, HIV, Washington, United States, ${ }^{2}$ Population Council Nigeria, Abuja, Nigeria, ${ }^{3}$ University of Michigan, Ann Arbor, United States, ${ }^{4}$ Population Council Nigeria, Lagos, Nigeria, ${ }^{5}$ Male Action Network, Abuja, Nigeria, ${ }^{6}$ The Independent Project (TIP) for Equal Rights- Nigeria, Lagos, Nigeria, ${ }^{7}$ At Time of Study, Population Council, New York, United States, ${ }^{8}$ Management Science for Health, Arlington, United States

UNAIDS Terminology Guidelines, October 2011. 


\section{List of Contributors}

\begin{tabular}{|l|l|l|}
\hline S/N & NAME & ORGANIZATION \\
\hline 1 & Dr. Sylvia Adebajo & Population Council \\
\hline 2 & Mr. Olusegun Sangowawa & Population Council \\
\hline 3 & Dr. George Eluwa & Population Council \\
\hline 4 & Ms. Lolade Abiodun & Population Council \\
\hline 5 & Dr. Otibho Obianwu & Population Council \\
\hline 6 & Dr. Segun Odumosu & Population Council \\
\hline 7 & Dr. Jean Njab & Population Council \\
\hline 8 & Mr. Godspower Omoreige & Society for Family Health (SFH) \\
\hline 9 & Mr. Chima Nwachukwu & Society for Family Health \\
\hline 10 & Ms. Iyabo Bello & Society for Family Health \\
\hline
\end{tabular}



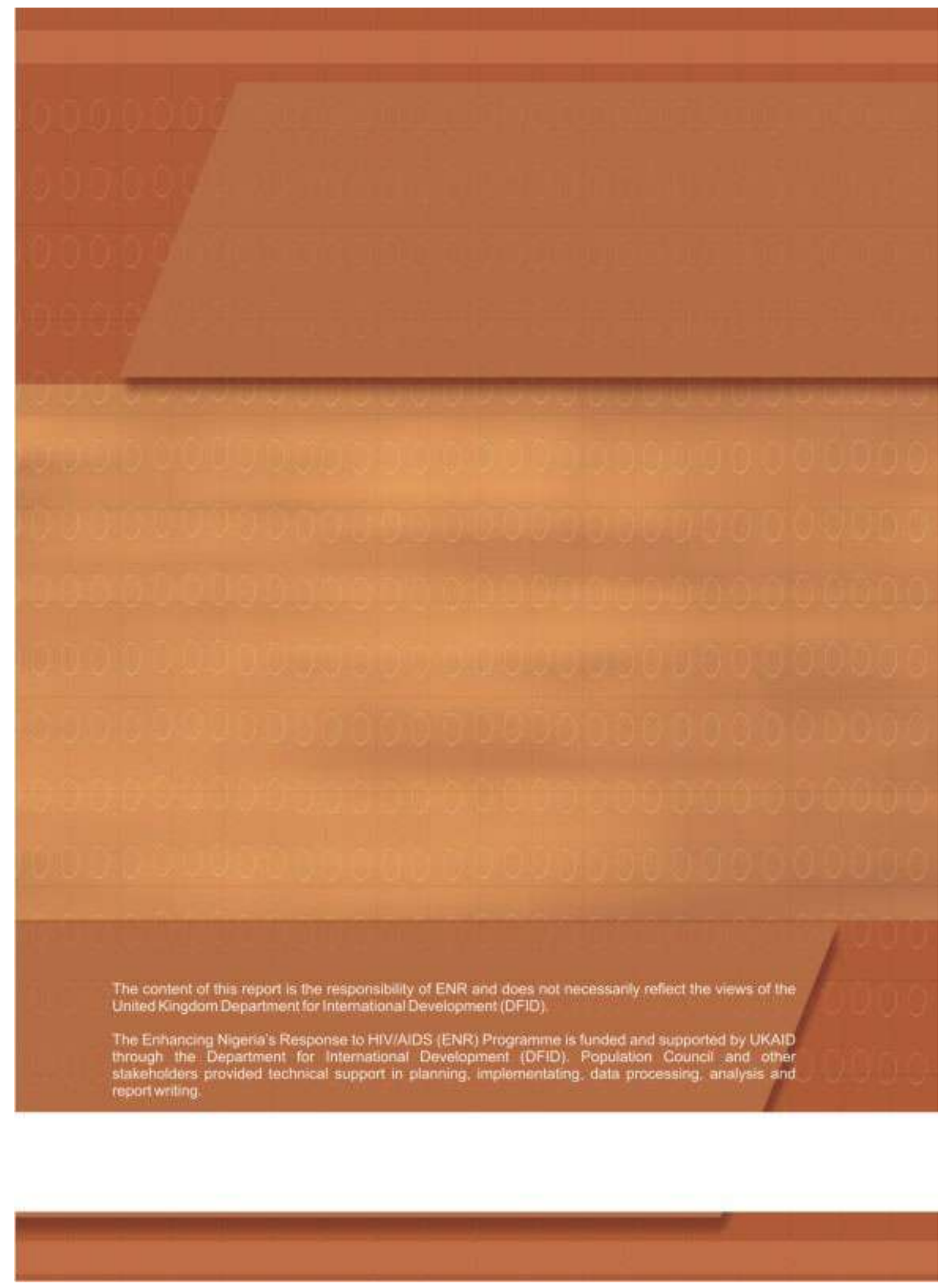